\section{Virusätiologie des Sudden Infant Death Syndrome}

Burkhard Madea, Jan Felix Drexler

\section{Definition}

Der Plötzliche Kindstod ist ein jahrtausendelang bekanntes Phänomen, von dem überwiegend Säuglinge im ersten Lebensjahr betroffen sind, die ohne vorherige Krankheitszeichen oder Störungen des Verhaltens tot im Bett aufgefunden werden. Allgemeine Diagnosekriterien des SIDS sind dabei:

- Plötzlicher unerwarteter Tod eines Kindes jünger als 1 Jahr

- Der tödliche Zwischenfall hat offensichtlich in der Nacht stattgefunden (vermutlich während des Schlafes)

- Die Todesursache bleibt nach sorgfältiger Untersuchung inklusive einer vollständigen Obduktion so wie einer Überprüfung der Todesumstände und der Krankengeschichte unklar.

Bereits früh wurde als ein Definitionsmerkmal des Plötzlichen Kindstodes oder „Sudden Infant Death Syndrome“ (SIDS) festgelegt, dass durch eine sorgfältige postmortale Untersuchung (Obduktion) inklusive morphologischer, histologischer, biochemischer und mikrobiologischer Anschlussuntersuchungen keine adäquate Todesursache nachweisbar ist. Nach den Kriterien der European Society for the Prevention of Infant Death (ESPID) werden heute folgende Kategorien des Plötzlichen Säuglingstodes unterschieden:

1. SIDS-Fälle im engeren Sinn, bei denen Obduktion und klinische Befunde keine Todesursache erkennen lassen.

2. Borderline-SIDS-Fälle, bei denen vorbestehende angeborene Erkrankungen, klinische Symptome und/oder Obduktion keine hinreichende Erklärung für die Todesursache geben.

3. Nicht-SIDS-Fälle, bei denen die Todesursache durch klinische Befunde oder das Obduktionsergebnis hinreichend erklärt ist.

4. Verdacht auf SIDS in Fällen, bei denen keine Obduktion durchgeführt wurde.

Da eine der wichtigsten Differentialdiagnosen des Plötzlichen Kindstodes Todesfälle durch gewaltsame Erstickung sind, wurden neuere Klassifizierungen des Plötzlichen Kindstodes um Untersuchungen des Sterbe- bzw. Auffindeortes erweitert ( Tab. 1). Da im Gegensatz zu den USA in Europa nur selten Leichenfundortbesichtigungen durch Rechtsmediziner durchgeführt werden, fallen die meisten Fälle in die Kategorie 1B (allgemeine Kenndaten und Diagnosekriterien des SIDS liegen vor außer Untersuchung des Leichenfundortes und/oder Durchführung von toxikologi- schen, mikrobiologischen, radiologischen, postmortal biochemischen Anschlussuntersuchungen). Das SIDS stellt eine reine Ausschlussdiagnose dar, die erst nach Obduktion und Durchführung weiterführender Untersuchungen möglich ist.

\section{Epidemiologie und Risikofaktoren}

In den Industrieländern ist der Plötzliche Kindstod nach wie vor die häufigste Todesursache in der Postneonatalperiode. Die SIDS Inzidenz ist jedoch in den letzten Jahren stark rückläufig $(0,461 / 1000$ Lebendgeborene gegenüber 1,55/1000 Lebendgeborene 1991). Laut Todesursachenstatistik wurden 2008215 Todesfälle der ICD-10 Position Nr. R95 „Plötzlicher Kindstod" zugeordnet.

Durch mehrere Fall-Kontrollstudien konnten folgende Risikofaktoren für den Plötzlichen Säuglingstod herausgearbeitet werden:

- Schlafen in Bauchlage

- Rauchen der Mutter während der Schwangerschaft

- Schlafen im Bett mit einem Erwachsenen

- Stillen unter 2 Wochen

- Externe Wärme während des Schlafs

- Kissen im Bett

- Geburtsgewicht < 2500 g

- Mehr als eine vorangegangene Geburt

- Alter der Mutter unter 20 Jahren

- Mutter lebt allein

Mit der Identifizierung vermeidbarer Risikofaktoren wie der Bauchlage von Säuglingen, wurden Präventionskampagnen zur Vermeidung des SIDS initiiert. Parallel zur Bauchlage-Prävalenz sank auch die postneonatale Mortalität und die SIDS Inzidenz.

\section{Ätiologie und Pathogenese}

Die Ätiologie und Pathogenese des SIDS ist nach wie vor ungeklärt. Es existieren in der Literatur mehr als 100 Theorien zur Ätiologie, die sich bislang alle als nicht tragfähig erwiesen haben.

Für eine infektiologische (Mit-)Ursache des SIDS sprechen folgende Befunde:

- In den letzten Tagen vor Todeseintritt häufig Infektionen der oberen Atemwege oder Enteritis.

- SIDS Inzidenz erhöht in der kalten Jahreszeit, welche gute Bedingungen für (virale) Infektionserreger schafft: Hohe Luftfeuchtigkeit, geringe UVStrahlung, Konzentration vieler Individuen auf engen Räumen.

- Häufig bei Auffindung erhöhte Körperkerntemperatur über $40^{\circ} \mathrm{C}$ oder durch Schwitzen durchfeuchtete Bekleidung oder Kissen.

- Bei der Obduktion Zeichen eines Infektes der oberen Atemwege.

Das Ausmaß der entzündlichen Infiltration der Atem- 
Tab. 1. Plötzlicher Kindstod - Definitionen und Diagnosekriterien (nach Krous et al. 2004)

Kategorie IA SIDS

Klassische Kenndaten des SIDS sind vorhanden und vollständig dokumentiert Jede der folgenden Voraussetzungen ist erfüllt:

\section{Klinisch:}

- Älter als 21 Tage und jünger als 9 Monate

- Unauffällige klinische Vorgeschichte einschließlich normaler Schwangerschaftsdauer $(\geq 37$ Wochen)

- Normales Wachstum und Entwicklung

- Keine ähnlichen Todesfälle unter Geschwistern, genetisch nahen Verwandten (Onkel, Tanten oder Cousins ersten Grades) oder anderen Kindern, die sich in der Obhut der gleichen Betreuungsperson befinden

\section{Todesumstände:}

- Untersuchung der Orte, an dem sich die zum Tode führenden Umstände ereignet haben können und Bestätigung, dass sie keine Erklärung für den Tod abgeben

- Die Schlafumgebung ist sicher und zeigt keine Anzeichen eines unfallbedingten Todes

\section{Obduktion:}

- Fehlen potentiell tödlicher pathologischer Befunde. Kleinere entzündliche Infiltrate des Atmungstraktes sind akzeptabel; intrathorakale petechiale Einblutungen sind ein unterstützender, jedoch nicht zwingender oder diagnostischer Befund

- Kein Nachweis eines unerklärten Traumas, Missbrauchs, Vernachlässigung oder unabsichtlichen Verletzung

- Kein Nachweis eines erheblichen Stresseffekts auf den Thymus

- Negative Resultate der toxikologischen, mikrobiologischen, radiologischen, postmortal biochemischen und Stoffwechseluntersuchungen

\section{Kategorie IB SIDS}

- Klassische Kenndaten des SIDS liegen vor, sind aber unvollständig dokumentiert

- Die Anforderungen der allgemeinen Definition werden erfüllt

- Alle Kriterien des Kategorie IA SIDS sind erfüllt, außer Untersuchung des Leichenfundortes und/oder der Durchführung einer der folgenden Analysen: Toxikologie, Mikrobiologie, Radiologie, postmortale Biochemie, Stoffwechselanalysen

\section{Kategorie II SIDS}

Kategorie II umfasst Todesfälle von Kindern, die die Kriterien der Kategorie I erfüllen außer $\geq$ der folgenden:

- Alter entspricht nicht Kategorie IA oder IB (d. h. 0-21 Tage oder 270 Tage (9 Monate) ab dem 1. Geburtstag

- Ähnliche Todesfälle unter Geschwistern, nahen Verwandten oder Kindern, die sich in der Obhut der gleichen Betreuungsperson befinden und die nicht unter dem Verdacht der Kindstötung oder anerkannter genetischer Anomalien stehen

\section{- Äußeres Ersticken oder Ersticken durch „Überliegen" nicht sicher fest- stellbar}
- Abnormales Wachstum und Entwicklung werden nicht als Mitursache für den Todeseintritt bewertet
- Ausmaß entzündlicher Veränderungen nicht ausreichend, um den Tod zu erklä- ren

wege und Lungen reicht jedoch nicht aus, den Todeseintritt zu erklären.

Da der Todeseintritt beim SIDS plötzlich ist, wurde unter anderem die Hypothese formuliert, dass die Ursache eine von einer Infektion der oberen Atemwege ausgehende Myokarditis sein könnte.

\section{Häufigkeit der Myokarditis im Kindesalter}

In älteren Untersuchungen wurde relativ selten in SIDS-Kollektiven eine Myokarditis nachgewiesen (0,5 bis $1 \%$ ); jüngere Untersuchungen berichten über eine höhere Inzidenz, teilweise bis $20 \%$.

Allgemein ist die Häufigkeit der Myokarditis nur schwer zu ermitteln, da die klinische Diagnostik schwierig ist und uneinheitlich gehandhabt wird. 


\section{Erregerspektrum}

In industrialisierten Ländern ist die virale Myokarditis die am meisten verbreitete Myokarditisform, von ätiologischer Bedeutung sind vor allem Picornaviren (insbesondere Coxsackie-A-und B-Viren), weiterhin Adenoviren, Herpesviren sowie Parvoviren B19.

Allgemein ist die Myokarditis eine seltene Todesursache im Kindesalter. Unter 1516 Obduktionen von Kindern im Alter bis 18 Jahren fanden sich 28 Fälle einer histologisch gesicherten Myokarditis (1,8 \%, Altersspanne von 10 Tagen bis 16 Jahren, Median 10 Monate). 16 dieser Kinder (57\%) starben plötzlich, mehr als die Hälfte der Fälle (54\%) betraf Kinder unter 1 Jahr. In 25 von 28 Fällen wurde eine virologische Untersuchung veranlasst. Hierbei konnte in 9 Fällen (36\%) virales Genom nachgewiesen werden $(6 \times$ Enteroviren, $2 \times$ Parvovirus B19, $1 \times$ Picornavirus). Bei 16 plötzlichen Todesfällen wurde nur $4 \mathrm{Mal}$ virales $\mathrm{Ge}$ nom nachgewiesen $(2 \times$ Enteroviren, $1 \times$ Parvovirus B19, $1 \times$ Picornavirus). Bei postmortalen Untersuchungen kann das Problem des "Sampling Errors“ durch eine hinreichend repräsentative Untersuchung des Myokards umgangen werden, um eine eventuell vorhandene fokale Infektion nicht zu übersehen.

\section{Diagnostik der Myokarditis}

\section{DALLAS-Kriterien}

Um eine standardisierte Diagnostik der Myokarditis an Endomyokardbiopsien zu ermöglichen, wurden vor mehr als 20 Jahren die DALLAS-Kriterien etabliert ( Tab. 2). Im Zentrum der konventionellen histologischen Diagnostik der Myokarditis anhand der DALLAS-Kriterien stehen dabei die Myozytennekrose, Myozytolyse, ein lymphomonozytäres Infiltrat sowie das interstitielle Ödem.

Eine aktive Myokarditis ist charakterisiert durch die Kriterien Nekrose, Myozytolyse, lymphomonozytäres Infiltrat sowie interstitielles Ödem. Bei einer Borderline-Myokarditis zeigt sich nur ein mäßiges lymphomonozytäres Infiltrat. Der weitere Verlauf einer Myokarditis wird bei Lebenden durch Endomyokardbiopsien überprüft.

Die DALLAS-Kriterien zur Diagnostik einer Myokarditis sind kritisiert worden, da eine Diagnostik am konventionell HE-gefärbten Schnitt nicht vor einer Zeitdauer von 24-48 Stunden post infectionem möglich ist, verschiedene Untersucher den gleichen Befund unterschiedlich bewerten („Interobserver Variability") und das Problem des "Sampling Error" besteht, der nicht hinreichend repräsentativen Untersuchung des Myokards bzw. von Endomyokardbiopsien.

So ist etwa die Frühphase einer Myokarditis Stunden post infectionem nur durch ultrastrukturelle oder molekularpathologische Methoden nachweisbar. Die konventionelle histologische Diagnostik ist erst nach ca. 24-48 Stunden möglich. Ca. ab 24-48 Stunden ist

\section{Tab. 2. DALLAS-Kriterien}

Erste Endomyokard-Biopsie

\begin{tabular}{|l|l|}
$\begin{array}{l}\text { Aktive Myokar- } \\
\text { ditis }\end{array}$ & $\begin{array}{l}\text { Myozytennekrose, Myozyto- } \\
\text { lyse, lympho-monozytäres } \\
\text { Infiltrat, interstitielles Ödem }\end{array}$ \\
\hline $\begin{array}{l}\text { Borderline- } \\
\text { Myokarditis }\end{array}$ & $\begin{array}{l}\text { nur spärliches lymphozytäres } \\
\text { Infiltrat }\end{array}$ \\
\hline
\end{tabular}

Kontroll-Biopsie

Persistierende Myokarditis weiterhin Myozytennekrose und Entzündung

Abnehmende Myokarditis

Abnahme des lymphomonozytären Infiltrats

Ausgeheilte Myokarditis

keine Myozytennekreose keine Myozytolyse keine lymphomonozytäre Infiltration

eine immunhistochemische Diagnostik möglich mit Nachweis der Expression nicht zellulärer proinflammatorischer Moleküle (Adhäsionsmoleküle, Zytokine). Eine Untersuchung mit postmortalen Endomyokardbiopsien bei Personen, die an einer histologisch gesicherten Myokarditis verstorben waren, ergab, dass aufgrund einer Biopsie die Diagnose Myokarditis lediglich in $25 \%$ der Fälle gestellt werden konnte. Mit mehr als 5 Biopsien konnte die Diagnose einer Myokarditis bei ca. 2/3 der Fälle gestellt werden, bei mehr als 17 Biopsien konnte die Diagnose in mehr als $80 \%$ der Fälle gestellt werden.

\section{Immunhistochemische Diagnostik}

Um eine möglichst frühzeitige Diagnostik der Myokarditis zu ermöglichen, hat sich in der klinischen Kardiologie heute der Einsatz molekularbiologischer Methoden und immunhistochemischer Färbungen an Endomyokardbiopsien etabliert. Aufgrund der immunhistochemischen Qualifizierung und Quantifizierung interstitieller Leukozyten, Makrophagen und TLymphozyten wurden Grenzwerte für die Diagnostik einer Myokarditis an Endomyokardbiopsien im Erwachsenenalter etabliert. Die Diagnose einer Myokarditis ergibt sich danach bei Nachweis von mehr als 10 Leukozyten, mehr als 6 Makrophagen bzw. mehr als 2-5 T-Lymphozyten pro High-Power-Field (HPF) bei 400facher Vergrößerung.

Daneben wird im Myokardgewebe mittels in-situ Hybridisierung bzw. PCR virales Genom detektiert. Dabei besteht allerdings keine strikte Korrelation zwischen immunhistochemischen und molekularbiologischen Befunden zum Nachweis viralen Genoms. So konnte bei 624 Patienten mit Myokarditis bzw. Bor- 
derline-Myokarditis in 239 Fällen (38 \%) virales Genom nachgewiesen werden (Adenoviren, Enteroviren, Zytomegalieviren). Die Diagnose einer Myokarditis kann sich isoliert auf einen der Diagnosestränge stützen.

\section{Diagnostik der Myokarditis am postmortalen Gewebe}

Die in der klinischen Kardiologie etablierten Methoden zur Diagnostik einer Myokarditis an Endomyokardbiopsien wurden inzwischen auf autoptisch gewonnene Gewebeproben von mutmaßlich am SIDS verstorbenen Säuglingen übertragen.

Für die immunhistochemischen und molekularpathologischen Untersuchungen wurde beispielhaft Myokardgewebe von acht Probeentnahmestellen asserviert (Herzkammerwand rechts, Septum interventriculare, Vorderwand linke Herzkammer, Hinterwand linke Herzkammer, jeweils basis- und spitzennah). Immunhistochemisch angefärbt wurden Leukozyten (LCA), T-Lymphozyten (CD45R0) und Makrophagen (CD68). Ausgezählt wurden 20 repräsentative Gesichtsfelder bei starker Vergrößerung mit anschließender Mittelwertbildung. Im SIDS-Kollektiv ergaben sich für Leukozyten, T-Lymphozyten und Makrophagen etwas höhere Zellzahlen, als in einem Kontrollkollektiv, das allerdings auch nur 11 Fälle umfasste. Aus der Verteilung der Zellzahlen in SIDS- und Kontrollkollektiv wurden „Grenzwerte“ für die Diagnostik einer Myokarditis abgeleitet. So soll sich die Diagnose einer Myokarditis bei mehr als 15 Leukozyten bzw. mehr als 10 T-Lymphozyten per HPF ergeben, eine Verdachtsdiagnose bei mehr als 5-9 T-Lymphozyten bzw. mehr als 10 Makrophagen. Bei Zugrundelegung dieser Grenzwerte würden nahezu $30 \%$ des SIDS-Kollektivs als Myokarditis bzw. myokarditisverdächtig eingestuft. Bei diesen Grenzwerten handelt es sich jedoch keineswegs um Diskriminanzwerte, die nur auf der Basis einer Verteilung der Zellzahlen zwischen Untersuchungs- und Kontrollstichprobe berechnet werden können. Bei Fall-Kontroll-Studien sollte die Kontrollgruppe immer doppelt bis dreifach so groß sein wie das Studienkollektiv. Dies ist vorliegend nicht der Fall. Weiterhin liegt den empfohlenen Grenzwerten für die Diagnostik einer Myokarditis eine nicht hinreichend repräsentative Auszählung des Gewebematerials zugrunde. Soweit eine „Auszählung in 20 repräsentativen Gesichtsfeldern bei starker Vergrößerung mit anschließender Mittelwertbildung“ bzw. „zufällige Auswahl der 20 repräsentativen Gesichtsfelder" empfohlen wird, ist dies nicht hinreichend, sondern würde bei 8 Probeentnahmestellen bedeuten, dass lediglich 2,5 Gesichtsfelder pro Präparat ausgezählt werden. Gerade vor dem Hintergrund bei Obduktionsmaterial wesentlich größerer Schnitte im Vergleich zu Endomyokardbiopsien ist es daher nicht überraschend, wenn sich bei Auszählung von 20 Gesichtsfeldern pro Prä- parat erhebliche Schwankungen der Zellzahlen von High-Power-Field zu High-Power-Field bzw. von Gewebsblock zu Gewebsblock zeigen. So variieren die Zellzahlen in einem Präparat ganz erheblich, so dass je nach Kombination der Gesichtsfelder sich die Diagnose einer Myokarditis ergibt oder eben nicht ergibt. Dies trifft in gleicher Weise auch beim Vergleich der Zellzahlen zwischen den 8 Probeentnahmestellen zu. Der hinsichtlich der Myokarditis-Diagnostik an Endomyokardbiopsien beschriebene "Sampling Error" trifft damit in gleicher Weise für postmortal gewonnenes Gewebe zu, wenn nicht hinreichend repräsentative Gesichtsfelder ausgezählt werden.

Dementsprechend ergab eine vergleichende Quantifizierung interstitieller Lymphozyten und Makrophagen bei SIDS-Fällen und Todesfällen durch Ersticken identische Zellzahlen im Myokard. Kleinere Infiltrate finden sich sowohl in SIDS- als auch Kontrollkollektiv. Darüber hinaus existiert bislang keine allgemein anerkannte Definition, welcher Schwellenwert einer Entzündung als todesursächlich akzeptiert werden kann. Die Quantifizierung interstitieller Leukozyten und Makrophagen an autoptisch gewonnenem Myokardgewebe stellt auf der Basis der bislang vorliegenden Untersuchungen keinen Fortschritt gegenüber der Myokarditis Diagnostik nach den klassischen DALLAS Kriterien dar, insbesondere, wenn dabei nicht auf Myozytennekrosen abgestellt wird.

Um ein Grading des Schweregrades und Ausmaßes einer Myokarditis zu ermöglichen, wurde die Einführung eines Entzündungsindex (Inflammatory Index) empfohlen. Dabei ist ein Entzündungsfokus definiert als Entzündungsherd mit Myozytennekrose. Eine Schweregradeinteilung ergibt sich daraus, wie viele Entzündungsfoci in wie vielen Schnitten nachweisbar sind. Bei einer spärlichen Entzündung liegen nur wenige Entzündungsherde auf wenigen Schnitten vor, bei ausgeprägten Entzündungen viele in nahezu jedem Schnitt. Der Entzündungsindex ergibt sich aus der Summe der Entzündungsherde pro Fall dividiert durch die Anzahl der untersuchten Schnitte und entspricht damit der durchschnittlichen Zahl der Entzündungsherde. Bei einer retrospektiven Analyse eines Erwachsenenkollektivs konnten 47 \% der Fälle als deutliche Myokarditis mit einem Entzündungsindex über 5 eingeordnet werden. Diagnostische Probleme ergeben sich auch hier bei einem nur geringen Schweregrad und geringer Ausdehnung der Entzündung. Vergleichbare Untersuchungen für das Kindesalter stehen bislang aus.

\section{Molekularbiologische Virusdiagnostik}

Zum molekularbiologischen Virusnachweis an paraffineingebettetem Myokardgewebe liegen inzwischen zahlreiche Untersuchungen vor. In einer 129 Fälle umfassenden SIDS-Stichprobe soll dabei in 38 Fällen virales Genom nachgewiesen worden sein, in einer Kon- 
trollstichprobe in keinem Fall. Krous et al. konnten demgegenüber in keinem ihrer 24 SIDS-Fälle virales Genom nachweisen, lediglich in der Kontrollstichprobe Enteroviren. In ersten eigenen Untersuchungen konnten lediglich Enteroviren nachgewiesen werden, sechsmal an Herz- und Lungengewebe, elfmal lediglich an paraffineingebettetem Myokard. Der molekulare Nachweis viraler Genombestandteile erfolgt in den meisten Studien unter Verwendung der Polymerasekettenreaktion (Polymerase Chain Reaction, PCR). Die hierfür benötigte Aufreinigung viralen Genoms aus Formalin-fixiertem paraffineingebetteten Material verursacht besondere Schwierigkeiten, da es insbesondere durch die Einwirkung des Formalins zu kovalenten RNA/DNA-Quervernetzungen und zu RNA/ DNA-Protein-Verbindungen kommt. Diese sehr stabilen Bindungen wirken sich sowohl auf die Aufreinigung, als auch den molekularen Nachweis mittels der PCR aus. Das aufgereinigte virale Erbmaterial ist zusätzlich durch mechanische Einwirkungen in der Regel stark vermindert und fragmentiert. Aufreinigung und PCR sollten deshalb auf relativ kleine virale Genomfragmente unter 300-400 Nukleotide Größe abzielen. Selbst unter solchen optimierten Bedingungen muss nach eigenen Daten mit einem Verlust viralen Genoms um mindestens den Faktor 100 gerechnet werden, weshalb sehr sensitive PCR Tests nötig sind, um virales Genom sicher zu detektieren. Prospektive Studien sollten neben sensitiven PCR Tests auf nicht Formalin-fixiertes Material setzen, um die Bedeutung viraler Infektionen für den plötzlichen Kindstod besser beurteilen zu können.

\section{Fazit}

Insgesamt ergibt sich damit derzeit kein Anhalt, dass eine Myokarditis einen wesentlichen zum Tode führenden Pathomechanismus bei als SIDS deklarierten Todesfällen darstellt.

\section{Literatur}

1. Artetz HT 1987 Myokarditis: the Dallas criteria. Hum Pathol 18:619-624

2. Bajanowski T, Vege A, Byard RW, Krous HF, Arnestad M, Bachs L, Banner J, Blair PS, Borthne A, Dettmeyer R, Fleming P, Gaustad P, Gregersen M, Grogaard J, Holter E, Isaksen CV, Jorgensen JV, de Lange C, Madea B, Moore I, Morland J, Opdal SH, Rasten-Almqvist P, Schlaud M, Sidebotham P, Skullerud K, Stoltenburg-Didinger G, Stray-Pedersen A, Sveum L, Rognum TO 2007 Sudden infant death syndrome (SIDS)-standardised investigations and classification: recommendations. Forensic Sci Int 165:129-143

3. Dettmeyer R 2008 Virusinduzierte Myokarditis beim mutmaßlichen plötzlichen Kindstod. Rechtsmedizin 18:365-376

4. Kitulwatte I D, Kim P J H, Pollanen M S (2010) Sudden death related myocarditis: A Study of 56 Cases. Forensic Sci Med Pathol 6:13-19

5. Krous HF, Ferandos C, Masoumi H, Arnold J, Haas AE, Stanley C, Grossfeld PD (2009) Myocardial Inflammation, Cellular Death, and Viral Detection in Sudden Infant Death Caused by SIDS, Suffocation, or Myocarditis. Pediatric Research 66 (1):17-21

6. Weber MA, Ashworth MT, Risdon A, Malone M, Burch M, Sibire J (2008) Clinicopathological features of paediatric deaths due to myocarditis: an autopsy series Arch Dis Child 93:594-598

\section{Vittaforma corneae}

Mikrosporidien

\section{Vulväre intraepitheliale Neoplasie (VIN)}

- Humane Papillomviren (HPV)

\section{Vogelgrippe}

Aviäre Influenzaviren

\section{Vogelzerkarien}

- Zerkarien

\section{VRE}

Enterokokken

\section{Vulvitis}

Candida

\section{Vulvovaginitis}

- Trichomonas vaginalis

\section{Vulvovaginitis herpetica}

- Herpes-simplex-Virus (HSV)

\section{Vulvakarzinom}

- Humane Papillomviren (HPV) 


\section{Wanderfilarie}

Loa loa

\section{Wanowrie-Fieber}

Bunyaviren

\section{Wanowrie-Virus}

- Bunyaviren

\section{Wanzen}

Ektoparasiten, sonstige (Stechmücken, Trombiculiden, Flöhe, Wanzen, Zecken)

\section{Wanzenstich}

Ektoparasiten, sonstige (Stechmücken, Trombiculiden, Flöhe, Wanzen, Zecken)

\section{Warze}

- Humane Papillomviren (HPV)

\section{Waterhouse-Friderichsen-Syndrom}

Neisseria meningitidis

\section{Watsonius watsoni}

- Darmegel

\section{Weeksella virosa}

- Flavobacterium

\section{Weicher Schanker}

Haemophilus ducreyi

\section{Weichteilinfektion}

- Capnocytophaga

- Clostridien der Gasbrandgruppe

- Edwardsiella

$\checkmark$ Eikenella

- Enterokokken

- Flavobacterium

- Fusobacterium

- Haemophilus influenzae

- Mykobakterien, nichttuberkulöse (NTM)

- Pasteurella multocida

- Porphyromonas

- Proteus mirabilis, Proteus vulgaris

- Providencia, Morganella

- Shewanella

- Staphylococcus aureus

- Stenotrophomonas

- Streptococcus pyogenes

\section{Weingartner-Syndrom}

- Brugia

\section{Weiße Piedra}

- Malassezia

- Trichosporon

\section{Welch-Fraenkel-„,Bazillus"}

-Clostridien der Gasbrand-Gruppe

\section{Wesselsbron-Virus (WSL-V)}

- Flaviviren, seltene humanpathogene

\section{West African eye worm}

$>$ Loa loa

\section{Western-Equine-Encephalitis-Virus}

Alphaviren 


\section{Western-Equine-Enzephalitis}

- Alphaviren

\section{West-Nil-Enzephalitis}

- West-Nil-Virus

\section{West-Nil-Fieber}

- West-Nil-Virus

\section{West-Nil-Meningitis}

- West-Nil-Virus

\section{West-Nil-Virus}

Erreger

Erregerspezies

West-Nil-Virus (abgek. WN-V)

\section{Taxonomie}

Das WN-V gehört zum Genus Flavivirus aus der Familie Flaviviridae. Ähnlich wie das serologisch eng verwandte Japanische Enzephalitis-Virus, Murray-Valley-Enzephalitis-Virus und St.-Louis-Enzephalitis-Virus ruft es neurologische Erkrankungen beim Menschen hervor.

\section{Historie}

Das WN-V wurde 1937 erstmals in der West-Nil-Provinz von Uganda gefunden. Immer wieder gab es sporadische Epidemien in Afrika, dem Mittelmeergebiet, Indien, Australien und Europa (z. B. 1996/97 in Rumänien und 1998 in Italien). In Nordamerika ist es 1999 bei einem Ausbruch in New York erstmals aufgetreten. Seitdem verbreitet es sich in dramatischer Weise über Nordamerika hinweg nach Kanada, Lateinamerika und in die Karibik aus.

\section{Morphologie}

Das WN-V gleicht morphologisch dem Gelbfiebervirus.

\section{Genom}

Die Länge der Genome der WN-V-Isolate variiert (10.842-11.057 Basen). Die Genome sind ähnlich wie dasjenige des Gelbfiebervirus organisiert (GenBankNr. M12294).

\section{Vermehrung}

$\mathrm{WN}-\mathrm{V}$ infiziert vermutlich dendritische Zellen an der
Einstichstelle und gelangt dann zu den regionalen Lymphknoten und in die Blutzirkulation (Primäre Virämie). Von dort ausgehend kann es weiter auf Endothelzellen und Zellen des retikuloendothelialen Systems übergreifen, so dass es zu einer sekundären Virämie kommt. Als Konsequenz kann sich das Virus schließlich in andere Organe und in das ZNS ausbreiten.

\section{Pathogenität / Virulenz / Antigenvariabilität}

Aufgrund der phylogenetischen Analyse der bisher gesammelten $\mathrm{WN}-\mathrm{V}$-Sequenzen können zwei genetische Linien unterschieden werden. Die Identität der Nukleotidsequenz zwischen diesen beträgt ca. $75 \%$. Die Linie 1 ist weiter in vier Clades (Indian, Kunjin, A, B) unterteilt und umfasst hauptsächlich Isolate aus Nord- und Zentralafrika, Europa, Israel, Australien und Nordamerika. Demgegenüber gehören Isolate aus Südafrika und Madagaskar zur Linie 2. Die wichtigen humanpathogenen Isolate gehören zur genetischen Linie 1.

\section{Erkrankung \\ West-Nil-Fieber, West-Nil-Meningitis, West-Nil- Enzephalitis}

\section{Inkubationszeit}

Die Inkubationszeit beträgt 3-5 Tage (in Einzelfällen bis zu 14 Tage).

\section{Symptome}

In den meisten Fällen der klinisch apparenten Infektionen (ungefähr $20 \%$ ) handelt es sich um eine relativ milde verlaufende, fiebrige $\left(>38^{\circ} \mathrm{C}\right)$, selbstlimitierende Erkrankung, die plötzlich beginnt und etwa 3-6 Tage andauert (West-Nil-Fieber). Außerdem treten Kopfschmerzen, Schwindel und Erbrechen auf. Über okuläre Schmerzen und Pharyngitis wird häufig berichtet. Einige Tage nach Fieberbeginn zeigt sich bei ca. $50 \%$ der Erkrankten ein makulopapuläres, nicht juckendes Exanthem. Gewöhnlich erscheint das Exanthem zuerst am Stamm, um sich schließlich auch auf Gesicht und Extremitäten auszubreiten. Der Ausschlag kann für eine Woche bestehen bleiben. Kinder erholen sich rasch. Dagegen kann bei Erwachsenen die Rekonvaleszenzphase protrahiert verlaufen. Die Prognose ist insgesamt gut. Todesfälle wurden bei älteren Personen vereinzelt beobachtet.

Nur bei $<1 \%$ kommt es in einer zweiten Krankheitsphase zu einer neuroinvasiven Infektion mit Meningitis, Enzephalitis oder schlaffer, Poliomyelitis-ähnlicher Lähmung. Die Inzidenz der ZNS-Symptomatik und die Letalität nehmen mit dem Alter zu und sind auch bei immunsupprimierten Patienten (z. B. nach Transplantation) höher. Prognostisch ist die WN-V-assoziierte akute schlaffe Lähmung (engl. acute flaccid paralysis, AFP) als ungünstig zu bewerten, da in der Regel 
keine Besserung der Lähmungserscheinungen eintritt (irreparabler Verlust der motorischen Axone).

\section{Pathophysiologie}

WN-V befällt neuronale Zellen insbesondere im Hirnstamm, in den tiefer gelegenen Kernstrukturen des Gehirns und in den Vorderhornzellen des Rückenmarks. Neben dem direkten zytopathischen Effekt des Virus auf Nervenzellen wird auch eine indirekte, durch antivirale Effektormechanismen des Immunsystems hervorgerufene, ZNS-Schädigung diskutiert. Altersabhängige Faktoren (verminderte Effizienz der antiviralen Immunantwort, größere Durchlässigkeit der BlutHirn-Schranke) begünstigen die Dissemination des Virus.

\section{Immunantwort}

Virusspezifische Antikörper werden benötigt, um die Virämie zu beenden. Mäuse, denen keine B-Zellen zur Verfügung stehen, sterben bei niedrigeren Virusdosen und weisen eine höhere Viruslast im ZNS auf als die immunkompetenten Kontrolltiere. Auch CD8 ${ }^{+}$-T-Zellen sind für die antivirale Immunabwehr wichtig. Diese Zellen können jedoch möglicherweise im Rahmen einer Immunpathologie auch zur Gewebeschädigung beitragen.

\section{Differenzialdiagnose}

Eine Infektion mit WN-V sollte bei akuter fiebriger Erkrankung und neurologischer Symptomatik immer in Erwägung gezogen werden, wenn der Patient aus einem Gebiet mit en- bzw. epizootischer WN-V-Aktivität stammt, kürzlich gegenüber Moskitos exponiert war oder eine Bluttransfusion bzw. ein Organtransplantat bekommen hat.

\section{Diagnostik}

\section{Untersuchungsmaterial}

Serum, Plasma, Liquor.

\section{Diagnostische Verfahren}

Nach Beginn der Symptomatik klingt die Virämie relativ rasch ab. Damit sind die Virusisolierung aus dem Blut und der Nachweis von WN-V-RNA im Blut selten und nur am Anfang der klinischen Phase erfolgreich. Nach Verschwinden der Virämie treten jedoch neutralisierende IgM- und IgG-Antikörper auf, so dass serologische Nachweismethoden greifen (HHT, NT, ELISA, IF). Bei Menschen mit ZNS-Symptomatik werden virusspezifische IgM-Antikörper im Liquor und Serum innerhalb von 5 Tagen nach Krankheitsbeginn gefunden. In diesem Fall wird auch bei ca. 50 \% der Patienten mit Hilfe der RT-PCR virale Nukleinsäure im Liquor - aber nur selten im Serum - detektiert. Der Nachweis von WN-V-RNA beweist eine WN-V-Infektion, der fehlende Nachweis schließt aber eine WN-VInfektion nicht sicher aus.

\section{Befund / Interpretation}

Da Kreuzreaktionen mit anderen Flaviviren auftreten, kann die Interpretation der herkömmlichen serologischen Untersuchungen bei Patienten mit einer früheren Flavivirus-Exposition Schwierigkeiten bereiten. Letzte Klärung muss dann der Neutralisations-Test (NT) bringen, der nur in Spezial-Labors (z. B. RobertKoch-Institut) durchgeführt wird.

\section{Therapie}

\section{Therapeutische Maßnahmen}

Eine wirksame spezifische Therapie der Infektionen mit WN-V existiert nicht. Es sind lediglich supportive Maßnahmen.

\section{Epidemiologie}

\section{Verbreitung}

Mittlerweile ist WN-V auf allen Kontinenten angekommen. In Afrika ist die WN-V-Infektion die am weitesten verbreitete Arbovirusinfektion. Das WNFieber kommt jedoch auch im mittleren Osten (z. B. Israel), in Südosteuropa (Mittelmeerraum, Portugal, Südfrankreich, Zypern und westliche Gebiete der früheren Sowjetunion) und in Indien vor ( Abb. 1). Seit dem ersten Ausbruch in Nordamerika (New York, 1999) verbreitet sich WN-V über Nordamerika hinweg nach Kanada, Lateinamerika und in die Karibik. Dabei kommt den Zugvögeln, die als Erregerreservoir dienen, eine Schlüsselrolle zu. Die eigentliche Übertragung findet jedoch durch Mücken statt. Ausbrüche der Erkrankung beim Menschen werden wie bei anderen Arbovirusinfektionen auch von klimatischen Faktoren stark beeinflusst. Schwere Regenfälle und hohe Temperaturen im Sommer führen zu einer dramatischen Zunahme der Aktivität der Culex-Moskitos und einem entsprechend hohen Risiko der Übertragung auf den Menschen. Eine saisonale Häufung im Sommer wird insbesondere in Ägypten und Israel beobachtet. Über aus den USA nach Deutschland importierte Fälle von WN-V-Infektionen beim Menschen wurde berichtet. Bei Wildvögeln in Deutschland konnte bisher das Virus nicht direkt nachgewiesen werden. Eine Einschleppung von WN-V nach Deutschland kann aber für die Zukunft nicht ausgeschlossen werden.

\section{Wirtsbereich / Reservoir}

$\mathrm{WN}-\mathrm{V}$ wird hauptsächlich in Rabenvögeln (Familie Corvidae) und Sperlingen (Familie Passeridae) amplifiziert, die als Reservoir für das Virus dienen und sehr empfindlich auf den Erreger reagieren (plötzlicher Tod dieser Vögel kann eine Epidemie unter Menschen ankündigen). In diesen Wirten kommt es zu einer ausgeprägten und lang anhaltenden Virämie. Daneben kann das Virus auch viele andere Vogelarten - die meist keine Symptome entwickeln - und eine Reihe von Haustieren (z. B. Pferde, Rinder, Ziegen, Hunde 


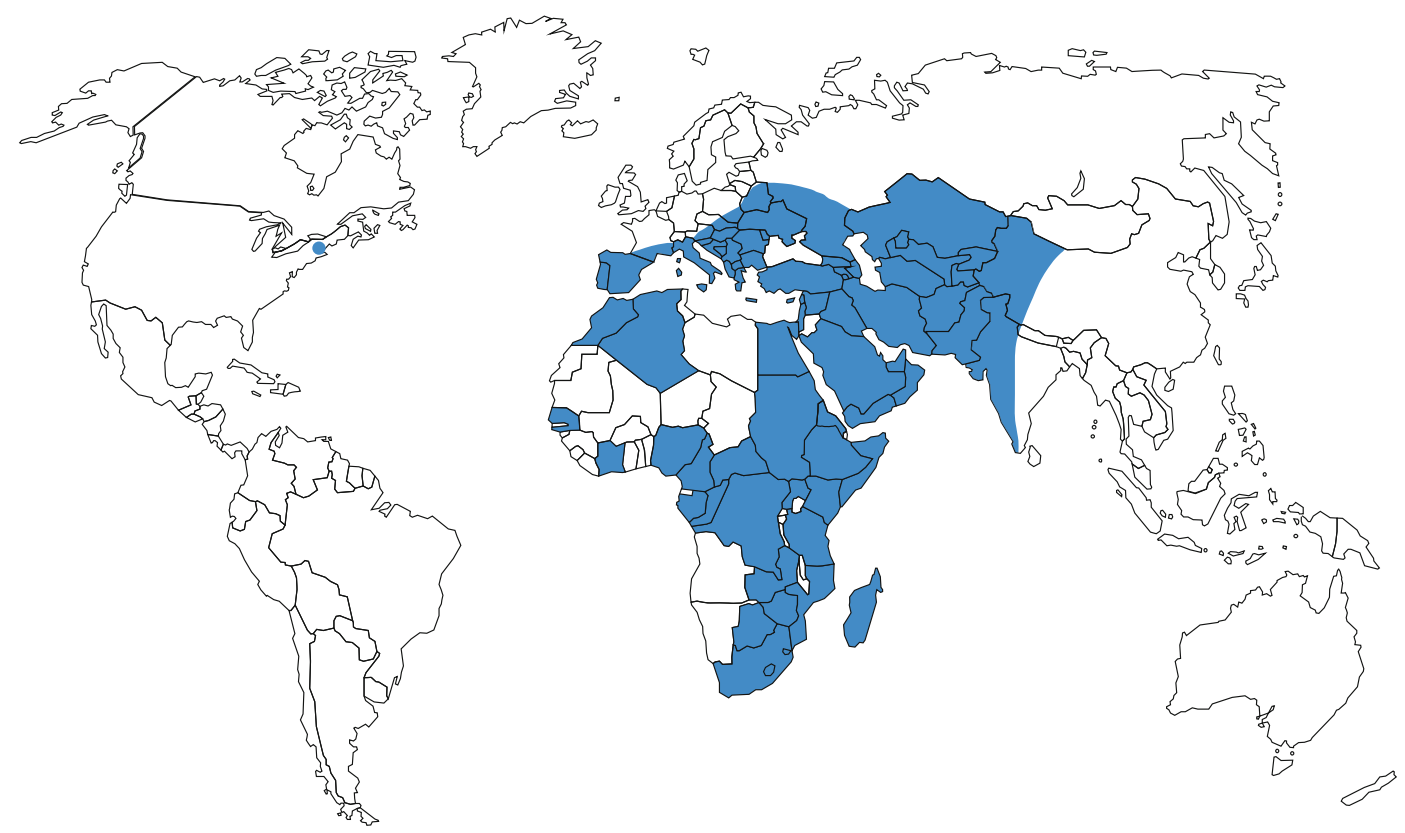

- Abb. 1. Verbreitung von West-Nil-Virus

und Katzen), wild lebenden Säugetieren und den Menschen infizieren. Säugetiere werden jedoch als Fehlwirte betrachtet, da hier nur eine kurze Virämie mit niedrigen Virustitern auftritt. Dies bedeutet, dass eine Übertragung von Mensch zu Mensch - direkt oder über Vektoren - praktisch nicht vorkommt. Ausbrüche in menschlichen Populationen stellen daher nur ein Überschwappen der ausgeprägten en- bzw. epizootischen Aktivität des Virus unter Vögeln dar. Möglicherweise spielt bei der Verbreitung unter Vögeln auch eine Arthropoden-unabhängige Übertragung durch Aufnahme von virushaltiger Nahrung eine Rolle (direkte Vogel-zu-Vogel-Transmission).

\section{Risikogruppen}

Hinsichtlich der Inzidenz eines schwereren Krankheitsverlaufs sind ältere Personen (> 60-70 Jahre) und Immunsupprimierte stärker gefährdet als andere. Eine Deletion im Chemokinrezeptor 5 (CCR5delta32), die bei $1 \%$ der weißen Bevölkerung vorkommt und vor HIV schützt, ist mit einem schwereren Verlauf der WN-V-Infektion assoziiert.

\section{Transmission / Vektoren}

Als Amplifikationsvektoren des WN-V innerhalb von Vogelpopulationen fungieren ornithophile Culex-Arten ( Abb. 2). Sog. Brückenvektoren, die sowohl Vögel als auch Menschen stechen, übertragen das Virus auf Menschen. Das Virus kann auch selten über Bluttransfusionen, Organtransplantationen und transplazentar weitergegeben werden. Wahrscheinlich können sich Kinder auch über die Muttermilch infizieren. Gelegentlich kommen Laborinfektionen vor.

\section{Prävention / Impfstoffe}

Programme, die zum Ziel haben, Moskito-Brutstätten $\mathrm{zu}$ vernichten, machen Gebrauch von Larviziden und Insektiziden (gegen adulte Mücken gerichtet). Sie führen aufgrund der vielschichtigen ökologischen Parameter, welche der Moskito-Verbreitung zugrunde liegen, nicht immer zum Erfolg.

Für den veterinärmedizinischen Einsatz gibt es einen Totimpfstoff (USA, Israel) und einen rekombinanten Lebendimpfstoff, der auf dem Canarypoxvirus als Vektor beruht. Ein Totimpfstoff (West Nile-Innovator $\left.{ }^{\circ}\right)$, der auf einem inaktivierten Vollvirus basiert, ist seit 2009 auch in Deutschland erhältlich. An der Entwicklung eines Impfstoffes für den Menschen wird intensiv gearbeitet. Dabei kommen WN-V-Totimpstoffe und verschiedene rekombinante Lebendimpfstoffe in Betracht. Aussichtsreicher Kandidat ist derzeit eine rekombinante Lebendvakzine, die auf dem erfolgreichen 17D-Impfstoff gegen Gelbfieber basiert und immunogene Proteine des WN-V enthält. Sie wird zurzeit klinisch getestet.

Moskito-Stiche sollten individuell vermieden werden. 


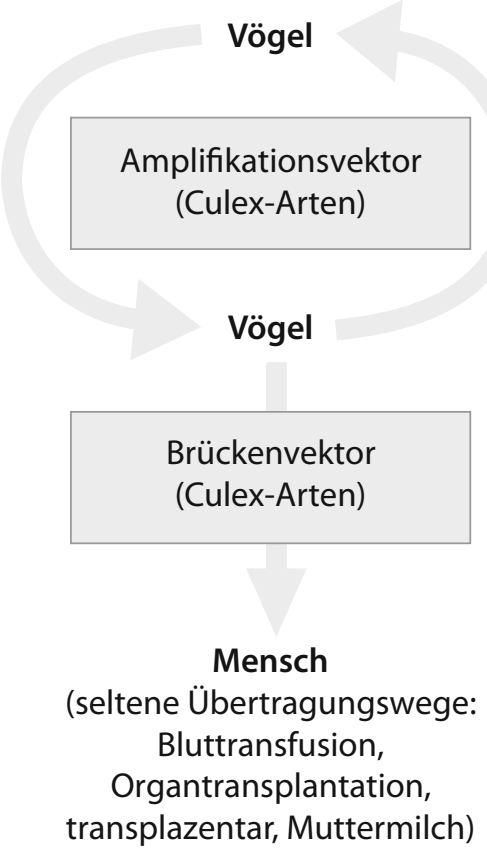

Abb. 2. Transmission des West-Nil-Virus. Vögel (Sperlinge, Rabenvögel) dienen als Amplifikationswirte für WN-V. Für die Zirkulation innerhalb von Vogelpopulationen sorgen ornithophile Culex-Arten. Hauptüberträger auf den Menschen (kein Amplifikationswirt) sind jedoch Culex-Arten, die als Brückenvektoren sowohl Vögel als auch Menschen stechen. Daneben gibt es weitere, seltene Übertragungswege.

Eingesetzt werden Insekten-Repellentien für Haut und Kleidung. Beispielsweise sind Anwendungen wirksam, die 10-50 \% N,N-Diethyl-m-toluamid (DEET) enthalten. DEET (z. B. Nobite) ist in Form von Sprays, Lotionen, Cremes, Gels oder als Seife verfügbar und besitzt ein breites Wirkungsspektrum (Mücken, Stechfliegen, Flöhe, Laufmilbenlarven und Zecken). Auch Piperidincarboxylsäure-hydroxyethyl-methylpropyl-ester (Autan ) stellt ein zuverlässiges Repellent dar. Zeltwände, Moskitonetze und Kleidungsstücke können mit dem Insektizid Permethrin behandelt werden. Zu beachten ist, dass die VektorMoskitos von der Dämmerung bis zum Morgengrauen aktiv sind. Das Tragen langer Kleidung und der Gebrauch von Moskitonetzen komplementieren den Schutz.

Blutspenden werden in den USA und Kanada durch RT-PCR auf WN-V untersucht. Dies ist in Deutschland nicht der Fall, so dass bis 4 Wochen nach Rückkehr aus Endemiegebieten (z. B. USA, Mexiko) kein Blut gespendet werden darf.

\section{Ausbruchsmanagement}

Als biologisches Frühwarnsystem für den Menschen werden oft Tiere (Hamster, Meerschweinchen, Ziegen, Hühner oder Tauben) an strategisch wichtigen Plätzen gehalten. Die WN-V-infizierten Moskitos befallen zuerst die Tiere. Daher wird deren Blut in regelmäßigen Abständen auf virusspezifische Antikörper untersucht. Nach Auftreten von Antikörper in den „Sondentieren" können die Behörden gezielt prophylaktische Maßnahmen ergreifen (Einsatz von Insektiziden, Vorsichtsmaßnahmen seitens der gefährdeten Bewohner zum Schutz vor Mückenstichen). In Nordamerika werden im Rahmen eines speziellen Überwachungsprogramms tote Rabenvögel auf WN-V-Infektion getestet.

\section{Meldepflicht}

Das WN-V stellt zwar in Deutschland derzeit keine Gefahr für die Allgemeinheit dar. Nach $₫ 7$ Abs. 2 des IfSG besteht jedoch Meldepflicht bei Krankheitserregern, die örtlich und zeitlich so gehäuft auftreten, dass mit einer schwerwiegenden Gefahr für die Allgemeinheit gerechnet werden muss. Mit Hilfe dieser Regelung sollen neu auftretende Krankheitserreger möglichst schnell identifiziert werden, um Gefahr für die Allgemeinheit abzuwenden. Weiterführende Informationen zum IfSG sind auf der unten aufgeführten Web-Adresse des Robert-Koch-Instituts zu finden.

\section{Weiterführende Informationen}

\section{Referenzzentren / Expertenlaboratorien}

- Nationales Referenzzentrum für tropische Infektionserreger, Bernhard-Nocht-Institut für Tropenmedizin, Bernhard-Nocht-Straße 74, 20359 Hamburg, Tel.: +49 40 42818-401 oder -400, E-Mail: MZD@bni-hamburg.de

- Nationales Referenzlabor für West-Nil-Virus, FriedrichLoeffler-Institut (FLI), Südufer 10, 17493 Greifswald-Insel Riems, Tel.: +49 383517-163, E-Mail: Martin.Groschup@ fli.bund.de

\section{Web-Adressen}

- Robert-Koch-Institut (RKI): http://www.rki.de/

- Friedrich-Loeffler-Institut (Nationales Referenzlabor für West-Nil-Virus): http://www.fli.bund.de/

- Bernhard-Nocht-Institut für Tropenmedizin (Hinweise auf Tropen-Viruskrankheiten): http://www.bni-hamburg. de/

- Gesellschaft für Virologie: http://www.g-f-v.org/

- Deutsche Vereinigung zur Bekämpfung der Viruskrankheiten e.V.: http://www.dvv-ev.de/

- Centers for disease control and prevention (Informationen zu West-Nil-Virus): http://www.cdc.gov/ncidod/dvbid/ westnile/

- Vetrinary Public Health (Tierärztliche Hochschule Hannover): http://www.veterinary-public-health.de/home_d/ aufgaben/zoonosen/

- WHO World Health Organization (Aktuelles über Infektionskrankheiten, Empfehlungen und Programme der WHO): http://www.who.int/ 


\section{Schlüsselliteratur}

1. Gubler DJ, Kuno G, Markoff L (2007) Flaviviruses. In: Knipe, DM, Howly, PM (eds) Fields Virology (5th edition) Philadelphia: Lippincott Williams and Wilkins, pp $1153-1252$

2. Kimberley AG (2009) West Nile virus infections. J Neuropathol Exp Neurol 68:1053-1060

3. Schoub BD, Venter M (2009) Flaviviruses. In: Zuckerman AJ, Banatvala JE, Pattison JR, Griffiths PD, Schoub BD, Mortimer P (eds) Principles and practice of clinical virology (6th edition) Chichester: John Wiley, pp 669-698

\section{Windpocken}

- Varicella-zoster-Virus (VZV)

\section{Windpockenvirus}

- Varicella-zoster-Virus (VZV)

\section{Wohlfahrtia spp.}

- Myiasis-Erreger

\section{Wolhynisches Fieber}

- Bartonella

Rickettsien

\section{Wolinella}

\section{Erreger}

Heinrich K. Geiss, Arne C. Rodloff

\section{Synonym(e)}

Keine.

\section{Erregerspezies}

Wolinella succinogenes

\section{Taxonomie}

$\varepsilon$-Gruppe der Proteobacteria; Ordnung: Campylobacterales Familie: Helicobacteriaceae: Genus: Wolinella

\section{Historie}

1961 beschrieb Wolin ein oxidasepositives, anaerobes Stäbchenbakterium aus dem Pansen von Kühen und nannte es Vibrio succinogenes. 1984 wurde diese Spezies zusammen mit den Arten W. curva und W. recta in die neue Gattung Wolinella klassifiziert. Aufgrund von Hybridisierungsexperimenten und $23 \mathrm{~S}$ rRNA-Untersuchungen wurden 1991 die beiden Arten W. curva und W. recta der Gattung Campylobacter (C. curvus, C. rectus) zugeordnet, sodass die Gattung Wolinella lediglich die Spezies W. succinogenes umfasst, deren komplettes Genom erstmals 2003 beschrieben wurde. Eine neue Wollinella-Art wurde 2003 erstmals beim Menschen in Zusammenhang mit Ösophaguskarzinom beschrieben.

\section{Morphologie}

W. succinogenes ist ein gramnegatives, nicht sporenbildendes, leicht gekrümmtes Stäbchenbakterium. Die Beweglichkeit wird hervorgerufen durch eine polare Geißel. Die Zellgröße liegt bei 0,4×1-4 $\mu \mathrm{m}$.

\section{Genom}

Accesion-Nummer: NC_005090 (W. succinogenes DSM 1740, complete genome).

\section{Vermehrung}

Eine Vermehrung von Wolinella succinogenes findet unter anaeroben bzw mikroaerophilen Bedingungen statt. Entsprechende Bedingungen finden sich im Darm von Mensch und Tier. In vitro bietet ein Gasgemisch aus $80 \% \mathrm{~N}_{2}, 15 \mathrm{CO}_{2}$ und $5 \% \mathrm{H}_{2}$ eine hinreichende Atmosphäre. Aufgrund der begrenzten Energieausbeute der anaeroben Glykolyse ist die Generationszeit z. B. gegenüber Enterobacteriaceae verlängert.

\section{Pathogenität / Virulenz / Antigenvariabilität \\ Unbekannt.}

\section{Erkrankung}

Krankheitsbezeichnung nicht bekannt.

\section{Diagnostik}

\section{Untersuchungsmaterial}

Biopsiematerial.

\section{Diagnostische Verfahren}

Die Anzucht und Isolierung aus menschlichem Material erfolgt unter anaeroben bzw. mikroaerophilen $\left(5 \% \mathrm{O}_{2}\right)$ Bedingungen. Feste Kulturmedien sollten für gute Wachstumsergebnisse bluthaltig (Kaninchen, Pferd, Schaf) und mit Hämin und Vitamin $\mathrm{K}_{1}$ supplementiert sein (Brucella-Agar, Columbia-Agar, Schädler-Agar). Wachstum auch in Flüssigmedien, die mit Formiat und Fumarat angereichert sind.

Biochemische Identifizierung: strikt asaccharolytisch, Oxidase- und $\mathrm{H}_{2} \mathrm{~S}$-positiv, Hauptmetabolit ist Succinat. Ansonsten negativ in vielen biochemischen Routinetests einschließlich Enzymsubstratreaktionen

\section{Epidemiologie}

\section{Verbreitung}

Unbekannt.

\section{Wirtsbereich / Reservoir}

Bislang ausschließlich im Rumen von Wiederkäuern nachgewiesen. 2003 erstmals Nachweis beim Menschen. 


\section{Risikogruppen}

Unbekannt.

\section{Transmission / Vektoren \\ Unbekannt.}

\section{Prävention / Impfstoffe}

Unbekannt.

\section{Ausbruchsmanagement \\ Nicht relevant.}

\section{Meldepflicht}

Keine.

\section{Weiterführende Informationen}

\section{Referenzzentren / Expertenlaboratorien}

- Institut für Medizinische Mikrobiologie und Infektionsepidemiologie des Universitätsklinikums Leipzig, Liebigstr. 21, 04103 Leipzig, Tel. 03419715200

\section{Web-Adressen}

Keine.

\section{Schlüsselliteratur}

1. Baar C, Eppinger M, Raddatz G, Simon J, Lanz C, Klimmek O, Nandakumar R, Gross R, Rosinus A, Keller H, Jagtap P, Linke B, Meyer F, Lederer H, Schuster SC (2003) Complete genome sequence and analysis of Wolinella succinogenes. Proc Natl Acad Sci USA 100:11690-11695

2. Bohr UR, Segal I, Primus A, Wex T, Hassan H, Ally R, Malfertheiner P (2003) Detection of a putative novel Wolinella species in patients with squamous cell carcinoma of the esophagus. Helicobacter 8:608-612

3. Tanner A, Paster BJ (1991) The Genus Wolinella. In: Balows A, Trüper HG, Dworkin M, Harder W, Schleifer K-H (Hrsg) The Prokaryotes. 2. Aufl, Springer Verlag, New York, Berlin, Heidelberg

4. Vandamme P, Falsen E, Rossau R, Hoste B, Segers P,Tytgat R, De Ley J (1991) Revision of Campylobacter, Helicobacter, and Wolinella Taxonomy: Emendation of Generic Descriptions and Proposal of Arcobacter gen. nov. Int J Syst. Bacteriol 41:88-103

\section{Wuchereria}

ACHim Höraur

\section{Erreger}

Synonym(e)

Bancrofti-Filarie.

\section{Erregerspezies}

Wuchereria bancrofti

\section{Taxonomie}

Klasse: Nematoda; Ordnung: Spirurida; Familie: Onchocercidae

\section{Historie}

Erste Beschreibung der Mikrofilarien 1863 durch De- marquay, der Adultwürmer 1877 durch Bancroft; Entdeckung der Larvenentwicklung in Stechmücken 1877 durch Manson. Zunächst bestand die irrige Annahme, die Infektion erfolge mit dem Trinkwasser, nachdem sich die Larven aus den sterbenden Mücken befreit haben. Erst viele Jahre später setzte sich die Erkenntnis durch, dass die Übertragung beim Saugakt des Insekts stattfindet.

\section{Morphologie}

Weißliche, fadenförmige Rundwürmer (Filarien); Männchen bis zu $40 \mathrm{~mm}$ lang und 0,1 mm dick, Weibchen 50-100 mm lang und 0,25 mm dick. Die Weibchen gebären Mikrofilarien $(270-320 \times 7-10 \mu \mathrm{m})$, die von einer Scheide (ursprüngliche Eihülle) umgeben sind.

\section{Genom}

Das Genom der nahe verwandten Spezies Brugia malayi wurde durchsequenziert und ist derzeit weitestgehend annotiert (siehe dort, sowie Web-Adressen von TIGR/USA und Sanger Center/UK). Derzeit besteht eine Initiative des NIH /USA zur Sequenzierung und Annotation des Genoms von W. bancrofti. Es wird angenommen, dass sich die Genomgröße nicht wesentlich von der von B. malayi unterscheidet (ca. 100$110 \mathrm{MB})$.

\section{Vermehrung}

W. bancrofti ist ein Helminth mit einem zweiwirtigen Entwicklungszyklus. Die einzige Vermehrungsphase ist dabei die geschlechtliche Vermehrung im Endwirt (natürlicherweise nur der Mensch). Die Weibchen produzieren während ihres ca. 5-10 Jahre währenden Lebens mehrere Millionen von Mikrofilarien, die lebend geboren werden. Die Mikrofilarien treten periodisch oder subperiodisch im peripheren Blut des Endwirts auf und werden durch den Zwischenwirt bzw. Überträger (vor allem Stechmücken der Gattung Anopheles in Afrika, sowie Culex und vereinzelt Aedes in Asien) beim Saugakt aufgenommen. Dort penetrieren sie die Magenwand und wandern in die Thoraxmuskulatur der Mücke ein. Nach zweimaliger Häutung innerhalb von 10 Tagen wachsen sie zur 1,4 mm langen Infektionslarve (L3) heran und wandern in die Stechborstenscheide ein. Beim nachfolgenden Saugakt der Mücke wandern die L3 auf die Haut des Endwirts und dringen aktiv durch den Stichkanal ein. Im Endwirt wandern sie in die Lymphgefäße; dort erfolgen über mehrere Monate die Häutung und das Heranwachsen zu Adultwürmern. Das erste Auftreten von Mikrofilarien im peripheren Blut (Präpatenz) geschieht nach 7-12 Monaten.

\section{Pathogenität / Virulenz / Antigenvariabilität}

Die Pathogenität wird hauptsächlich durch das adulte Stadium hervorgerufen. Beim Absterben von adulten Würmern kommt es zu einer plötzlichen Freisetzung 
von großen Mengen von Antigen. Dies führt zu einer fieberhaften Lymphangitis und Lymphadenitis „Filarienfieber").

Neben den Wurmantigenen, die eine klassische Eosinophilen- mit nachfolgender Makrophagenantwort hervorrufen, scheinen auch die mit den Filarien in Symbiose lebenden Wolbachia-Endobakterien eine pathogenetische Rolle zu spielen; letztere induzieren die Freisetzung u. a. von TNF aus Makrophagen. Dies hat wiederum die Ausschüttung von Angiogeneseund Lymphangiogenesefaktoren (VEGF, bFGF, u. a.) zur Folge, wodurch es zu einer proliferativen Veränderung des Lymphendothels kommt.

Mikrofilarien enthalten eine Gamma-Glutamyl-Transpeptidase; Homologe dieses Proteins sind als Immunogene bzw. Allergen bekannt. Hyperreaktivität gegen dieses Protein scheint eine Immunantwort hervorzurufen, die erfolgreich Mikrofilarien abtöten kann; solchermaßen angegriffene Mikrofilarien können aber im Kapillarbett der Lunge die Tropische Pulmonale Eosinophilie (TPE) auslösen.

Bei der Mehrzahl der Infizierten kommt es jedoch zu einer Immunsupression, so dass hohe Wurmlasten ohne Krankheitszeichen toleriert werden. Die Mechanismen dürften ähnlich denen bei Onchozerkose sein (s. dort). Patienten ohne Mikrofilarien im Blut (latente Infektion, s. u.) zeigen höhere pro-inflammatorische Th1-, Th17- und Th2-Antworten im Vergleich zu mikrofilarämischen Patienten.

\section{Erkrankungen}

\section{Lymphangitis/Lymphadenitis}

\section{Synonym(e)}

Filarienfieber.

\section{Inkubationszeit}

Einige Jahre (Absterben der adulten Würmer, mittlere Lebenszeit 5-10 Jahre).

\section{Leitsymptome}

Lymphknotenschwellung, Fieber, Schmerzen im befallenen Bereich (meist Arm oder Bein, einseitig).

\section{Symptome}

Akut auftretendes Fieber $>38^{\circ} \mathrm{C}$, verbunden mit Schmerzen und Überwärmung bevorzugt im Bereich der vergrößerten Lymphknoten, Rötung der Lymphbahnen. Insbesondere der femorale Lymphknoten kann dabei abszedieren und nach außen durchbrechen. Typisch sind bleibende große Narben. Die Fieberattacken können mehrmals pro Jahr auftreten und dauern mehrere Tage bis zu einer Woche.

Nicht selten spielen sich beim Mann die Entzündungen des Lymphgefäßsystems im Genitalbereich $a b$, was zu Funiculitis, Epididymitis und Orchitis führt.

\section{Pathophysiologie}

Die Symptome entstehen durch das (natürliche oder durch Medikamente induzierte) Absterben von adulten Würmern. Der lokal in den Lymphbahnen auftretende Entzündungsreiz führt zur Entzündung der Lymphgefäße (Lymphangitis) wie auch der zugehörigen Lymphknoten (Lymphadenitis).

\section{Immunantwort}

Das Absterben der Würmer führt zu einer Freisetzung sowohl von „klassischen“ Wurmantigenen, welche eine antikörperabhängige zelluläre Zytotoxizitätsantwort (,antibody dependent cellular cytotoxicity“, ADCC) mit Beteiligung von Eosinophilen und Makrophagen induzieren als auch von Antigenen der Wolbachia-Endobakterien, die eine typische Sofortreaktion (Toll-like-Rezeptor-vermittelt) gegen Bakterien ähnlich einer Sepsis hervorrufen. Wichtige Mediatoren sind hier TNF, IL-6, IL-1, und IL-8.

\section{Differenzialdiagnose}

Lymphangitis und Lymphadenitis bakterieller Genese, z. B. durch Streptokokken bzw. Chlamydia trachomatis. Da Bakterien-Nachweise (zumal in den abgelegenen Gebieten in den Tropen) schwierig sind, wird die Diagnose zum einen klinisch unter Berücksichtigung der Endemizität, zum anderen parasitologisch durch Beweis einer Infektion mit $W$. bancrofti spp. (siehe unten) gestellt. Dies muss allerdings auch die Untersuchung auf zirkulierendes Filarienantigen (CFA, s. u.) umfassen.

\section{Elefantiasis}

\section{Synonym(e)}

Filarienbedingtes Lymphödem.

\section{Inkubationszeit}

Die Erkrankung tritt bei Personen, die im endemischen Gebiet geboren wurden, ab dem 15. Lebensjahr auf. Infizieren sich Personen, die aus nicht endemischen Gebieten stammen, dann können diese bereits innerhalb von 1-2 Jahren Zeichen einer Elefantiasis entwickeln. Es gibt epidemiologische Hinweise dafür, dass eine maternal übertragene Immuntoleranz gegenüber Filarienantigenen dazu führt, dass die Parasitenlasten höher ausfallen, gleichzeitig aber die Erkrankungen milder verlaufen.

\section{Leitsymptome \\ Lymphödem, Elefantiasis.}

\section{Symptome}

Ödematöse Schwellung der Gliedmaßen, meist der Beine. Im Gegensatz zur Filariose durch B. malayi sind beim Mann oft auch Ödeme des Genitales (Skrotalödem) zu finden, da sich die Würmer bevorzugt im Skrotalbereich aufhalten und sich somit Entzündungsvorgänge dort manifestieren.

\section{Pathophysiologie}

Durch die wiederkehrenden Entzündungsantworten 
in den Lymphbahnen kommt es bei genetisch prädisponierten Infizierten (familiäre Häufung!) zu einer entzündlichen Proliferation des Lymphendothels mit Erweiterung der Lymphgefäße, deren Klappen durch die Erweiterung insuffizient werden, sodass der Lymphfluss gestört ist, d. h. er erfolgt nicht mehr in Richtung des Herzens, sondern entsprechend der Schwerkraft retrograd. Langsam entwickelt sich ein (wegen des hydrostatischen Druckes beinbetontes) Lymphödem.

Zusätzlich sind, v. a. im Skrotalbereich, auch entzündlich bedingte Abflussstörungen in den Lymphbahnen als ursächlich für den Lymphstau anzusehen.

Wie bei Lymphödemen anderer Genese, so gilt auch bei der Elefantiasis, dass bei einer Vorschädigung des Lymphsystems andere exogene infektiöse Erreger, die durch kleinste Hautverletzungen eindringen, ebenfalls zu Fieberattacken mit weiterer Entzündung führen können, sodass sich das Geschehen auch ohne den ursprünglichen Erreger verselbstständigt und progredient verläuft.

\section{Immunantwort}

Die Freisetzung von Antigenen des Wurms und der Wolbachia-Endobakterien in den Lymphbahnen geschieht nicht nur akut beim Absterben von Adulten, sondern wohl auch chronisch durch Freisetzung degenerierter Mikrofilarien (ca. 30 \% der produzierten Mikrofilarien), die von Eosinophilen und Makrophagen abgeräumt werden. Dies führt zu einer chronischen Induktion von inflammatorischen Zytokinen (TNF etc. E Erkrankung 1: Immunantwort) und in der Folge von Wachstumsfaktoren für die Angiogenese (VEGFA) und Lymphangiogenese (VEGF-C und -D).

Es wird diskutiert, ob die beobachteten familiären Häufungen ihre Ursache in allelischen Varianten der VEGFs haben, die eine stärkere Lymphproliferation induzieren. Auch für eine genetisch bedingte stärkere Immunabwehr gegenüber heranwachsenden Würmern gibt es Anhaltspunkte, und Lymphödem-Patienten eliminieren nicht selten die Würmer und haben keine Infektionszeichen außer einer Serumnarbe mehr.

\section{Differenzialdiagnose}

Lymphödeme anderer (nicht infektiöser) Genese (Verletzungen, iatrogen). In Gegenden mit vulkanischem Boden kann es durch Aufnahme von Silikaten zur so genannten Podokoniose kommen. Die Lymphödeme sind klinisch kaum von den durch Filarien induzierten zu unterscheiden. Zur Differentialdiagnose steht allerdings die Serologie (Serumnarbe) im Vordergrund, da die stärkere Immunabwehr (siehe oben) dieser Patienten die Parasiten meist unter die Nachweisgrenze drückt oder neue Infektionen sogar ganz verhindert. Nicht selten haben Patienten, die ein Lymphödem ursächlich durch $W$. bancrofti bekommen haben, bei oder kurz nach der klinischen Manifestation keine Parasiten mehr.

\section{Hydrocele / Chylozele}

\section{Synonym(e)}

Keine.

\section{Inkubationszeit}

5-20 Jahre.

\section{Leitsymptome}

Hydrocele.

\section{Symptome}

Absonderung von seröser Flüssigkeit zwischen die Blätter der Tunica vaginalis des Skrotums im männlichen Genitale, bei der Chylozele findet sich zusätzlich chylöses Material wie Chylomikronen und Lipide Es kommt zu einer zunehmenden, prall-elastischen Füllung dieses Raums. Die Größe variiert von subklinischen Formen (nur in der Ultraschalluntersuchung zu sehen) bis zu Kindskopfgröße (Extrem).

\section{Pathophysiologie}

Ähnlich wie beim Lymphödem ist bei der Hydrozele zunächst von einer entzündlichen Proliferation des Lymphendothels auszugehen. Die post-entzündlichen Heilungsprozesse führen $u$. a. auch zu Störungen der Drainage der Flüssigkeit zwischen den Blättern der Tunica. Hinzu kommt eine durch die Entzündung verstärkte Sekretion von seröser Flüssigkeit in die Tunica. Bei der Chylozele kommt es zu einem Anschluss an das Lymphsystem und retrogradem Influx von Lymphe, was zur Hodennekrose führen kann; deshalb muss diese Form rasch operiert werden.

\section{Immunantwort}

Ähnlich wie beim Lymphödem. Es konnte gezeigt werden, dass bestimmte allelische Varianten von VEGF-A signifikant mit dem Auftreten einer Hydrocele vergesellschaftet sind.

\section{Differenzialdiagnose}

Im Ultraschall stellt sich bei einer Hydrozele die Flüssigkeit klar dar, während bei einer Chylozele echodichte Punkte imponieren (Lipidaggregate, Chylomikronen?); die Differenzierung ist wichtig wg. der therapeutischen Konsequenzen. Die wichtigste Differentialdiagnose ist die v. a in Afrika häufige Leistenhernie. Im Gegensatz zur palpatorisch prall-elastischen Hydrocele ist die Leistenhernie i. d. R. reponierbar, der Inhalt nicht wie bei der Hydrocele mittels Diaphanoskopie mit einer Taschenlampe durchscheinend. Auch mittels Ultraschalldiagnostik kann die mit Darmschlingen gefüllte Hernie von der mit Flüssigkeit gefüllten Hydrocele gut unterschieden werden.

\section{Tropische Pulmonale Eosinophilie, TPE}

Während die Ätiologie einer Infektion mit Brugia malayi bei der TPE unumstritten ist (weil das Auftreten mit dem Verbreitungsgebiet von Brugia korreliert), 
kommt es bei Wuchereriasis sicher seltener zu einer TPE. Oft kann eine Brugiasis dann nicht sicher ausgeschlossen werden, weil die TPE in der Regel amikrofilarämisch verläuft und somit kein Parameter zum Ausschluss einer Brugiasis zur Verfügung steht.

\section{Synonym(e)}

Okkulte Filariose, Tropisches eosinophiles Asthma.

\section{Inkubationszeit}

Monate bis Jahre nach Infektion.

\section{Leitsymptome}

Asthmoide Bronchitis.

\section{Symptome}

Asthmoide Bronchitis, Husten, Störung des Allgemeinbefindens, radiologisch Lungeninfiltrate mit vergrößerten Lymphknoten, laborchemisch hochgradige Eosinophilie (i. d. R. > $20 \%$ und mehr).

\section{Pathophysiologie \\ - Brugia malayi}

\section{Immunantwort}

$\checkmark$ Brugia malayi

\section{Differenzialdiagnose}

Lungenerkrankungen anderer Genese, infektiöse (Tbc) wie nicht infektiöse (Tumoren). Hinweisgebend ist die hohe Eosinophilie sowie IgE-Titer auf Filarienantigene.

\section{Diagnostik}

\section{Untersuchungsmaterial}

Im Gegensatz zur Brugiasis ist die derzeit sensitivste Methode zur Diagnose einer Wuchereriasis nicht der Nachweis von Mikrofilarien (mikroskopisch oder mittels PCR), sondern die Bestimmung von zirkulierendem Filarienantigen im Blut. Dieses Antigen wird von adulten Würmern sezerniert, auch wenn keine Mikrofilarien im Blut nachweisbar sind. In Endemiegebieten ist mit solchen okkulten Infektionen in ähnlicher Höhe wie mit patenten Infektionen zu rechnen! Das Antigen ist im Serum nachzuweisen, unterliegt keiner Periodizität und ist hitzestabil, so dass die Proben nicht gekühlt werden müssen.

Mikrofilarien zur Bestimmung einer patenten Infektion können mittels Mikroskopie oder PCR aus antikoaguliertem Blut (bei PCR nicht heparinisiert, sondern EDTA-Blut!) nachgewiesen werden. Die Blutentnahme zum Mikrofilariennachweis muss je nach Endemiegebiet und Periodizität der Mikrofilarien erfolgen. Bei der weitaus häufigsten „Microfilaraemia nocturna" schwärmen die Mikrofilarien nachts in das periphere Blut aus, verschwinden dagegen während des Tages fast völlig und sind dann nur bei sehr hohem Befall (> $1000 \mathrm{MF} / \mathrm{ml})$ nachweisbar. Die günstigste Zeit für die Blutentnahme liegt zwischen 21 und 2 Uhr (bei Übertragung am Tage durch Aedes dagegen zwischen 15 und 17 Uhr). Durch eine Provokation mittels einer oralen Gabe von 100 mg DiäthylcarbamazinCitrat erhöht sich die Mikrofilarämie nach 30-60 min (Cave: in Afrika muss vor einer Provokation das Vorliegen einer Onchozerkose ausgeschlossen werden!). Die Blutentnahme für die Serologie kann jederzeit erfolgen.

Zur Anreicherung für Mikrofilarien eignen sich drei Verfahren (genaue Beschreibung $\triangleright$ Brugia):

- Mikrohämatokritverfahren,

- Anreicherung durch Lyse von Erythrozyten,

- Anreicherung durch Filter.

\section{Diagnostische Verfahren}

Bestimmung des zirkulierenden Filarienantigens („Circulating filarial antigen“, CFA)

Es gibt zwei kommerziell erhältliche Tests: einen ELISA (das dort nachgewiesene Antigen trägt die Patentbezeichnung Og4C3) der Firma TropBio (Townsville, Australien) sowie einen Kartentest (ICT) der Firma Binax (Scarborough, Maine, USA; www. binax.com) mit herstellerspezifischen Grenzwerten. Der Nachweis von CFA ist für Wuchereriasis spezifisch und beweist das Vorliegen einer Infektion auch im Falle eines negativen Mikrofilariennachweises, was für die Interpretation bei Vorliegen von lymphatischer Pathologie sehr wichtig ist (siehe unten).

\section{Nachweis von Mikrofilarien}

Für den Nachweis von Mikrofilarien bieten sich folgende Verfahren an:

- Nativpräparat siehe Brugia.

- Dicker Tropfen, Methode $>$ Malaria.

- Die Delafield'sche Färbung anstelle der GiemsaFärbung erlaubt eine bessere Visualisierung der Kerne im Schwanzbereich der Mikrofilarien. Werden Mikrofilarien beurteilt, so lassen sich differenzialdiagnostisch Wuchereria-Mikrofilarien von den Mikrofilarien anderer Filarienarten durch die sie umgebende Scheide, aufgelockert gelagerte Kerne, ein kernfreies Schwanzende sowie einen kurzen kernfreien Kopfabschnitt unterscheiden.

\section{PCR}

Wenn speziesspezifische Primer verwendet werden, erlaubt sie eine Speziesdifferenzierung auch für den in der Mikroskopie nicht geübten Untersucher. „Inhouse-Tests" sind beschrieben (Einsendung an Speziallabore). Im Vergleich zur Mikroskopie von Blut-MF ohne Anreicherungsverfahren ist die PCR sensitiver und erlaubt eine Materialentnahme ohne Beachtung der Periodizität. Allerdings muss auch für die PCR theoretisch mindestens eine MF im Untersuchungsmaterial vorhanden sein, und bei den Infektionen mit Blut-MF kann man durch die Anreicherungsverfahren die Sensitivität der Mikroskopie um den Faktor 100 und mehr steigern. 


\section{Serologische Diagnostik}

Mittels Immunfluoreszenz-Test (IFT, Gefrierschnitte von adulten Filarien als Antigen; es können auch tierische Filarien verwendet werden) oder ELISA.

\section{Weitere Diagnostik}

Die Untersuchung auf sich bewegende Würmer in Lymphbahnen mittels Ultraschall des männlichen Skrotalbereiches wird mit einer 3-5 $\mathrm{MHz}$ Sonde durchgeführt. Zur Abgrenzung des Bewegungsmusters von Filarien („,filarial dance sign“, FDS) von dem kleiner Gefäße mit rhythmischem Puls empfiehlt sich, zusätzlich einen gepulsten Doppler („pulse wave doppler") zu verwenden, der das Bewegungsmuster über die Zeit aufnimmt.

\section{Befund / Interpretation}

Das klinische Bild in Zusammenhang mit der Herkunft des Patienten lassen eine Verdachtsdiagnose zu. Klinisch liefern rekurrierende Lymphangitiden und Lymphadenitiden unter Berücksichtigung der Herkunft des Patienten wichtige Verdachtshinweise auf eine Wuchereria-Infektion, ebenso eine Elefantiasis bei Patienten aus Endemiegebieten.

Beweisend für eine Wuchereriasis ist der Nachweis von CFA im Serum oder Plasma des Patienten oder der Nachweis eines FDS im Ultraschall. Diese beiden Methoden weisen auch die okkulte Wuchereriasis nach, die nach neuen epidemiologischen Daten etwa genauso häufig ist wie die patente Infektion, bei der Mikrofilarien nachweisbar sind, und die ursächlich sogar häufiger mit Pathologie assoziiert ist als die patente Infektion. CFA-Positivität sowie der Nachweis von FDS im Skrotalbereich sind gleichzeitig auch für die Wuchereriasis spezifisch (Abgrenzung zur Brugiasis u. a.). Die skrotale Ultraschalluntersuchung bringt $\mathrm{zu}>70-80 \%$ positive Befunde bei CFA-positiven Patienten. In den meist erweiterten Lymphbahnen sind die Würmer an ihrer charakteristischen Bewegung zu erkennen. An anderen Lokationen (z. B. Lymphbahnen der Wade und des Oberschenkels) sowie bei Frauen ist diese Methode weniger verlässlich.

Die Resultate beider serologischer Verfahren sind filarien-, jedoch nicht artspezifisch, und somit geeignet zur Abgrenzung von Infektionen mit anderen Würmern und zur Beurteilung einer früher durchgemachten Infektion.

Bei der Elefantiasis ist der Mikrofilarienbefund in der Regel, bei der TPE fast immer negativ. Immunologische Ergebnisse lassen den Schluss zu, dass eine inverse Relation besteht zwischen der Menge der Mikrofilarien und dem Ausmaß an inflammatorischer immunologischer Reaktivität bzw. dem Auftreten von Pathologie und Krankheitszeichen.

\section{Therapie}

\section{Therapeutische Maßnahmen}

Es ist grundsätzlich zwischen Massenchemotherapie in Endemiegebieten und der Individualtherapie zu unterscheiden, da bei ersterer eine suboptimale Wirkung (z. B. nur mikrofilarizid) zugunsten der Verabreichungsmöglichkeit in einer Einzeldosis $1 \times / \mathrm{Jahr}$ in Kauf genommen wird.

- Massenchemotherapie $>$ Ausbruchsmanagement.

- Individualtherapie: Wegen der durch die adulten Würmer induzierten Pathologien sind rein mikrofilarizid wirkende Mittel zur Therapie der Wuchereriasis nicht ausreichend. Als Mittel der Wahl galt lange Zeit das Diäthylcarbamazin (DEC), das in einer Dosierung von entweder $6 \mathrm{mg} / \mathrm{kg}$ KG für 12 Tage oder bei hohen MF-Lasten einschleichend (1. Tag: $1 \times 50 \mathrm{mg}, 2$. Tag $3 \times 50 \mathrm{mg}, 3$. Tag $3 \times 100 \mathrm{mg}$, ab 4 . Tag $3 \times 150 \mathrm{mg}$ (was $6 \mathrm{mg} / \mathrm{kg} \mathrm{KG}$ entspricht) gegeben wird. Bei Nebenwirkungen (Fieber, bei Männern vorübergehende Bildung schmerzhafter Knoten im Skrotum beim Absterben adulter Würmer) gibt man $3 \times 1-2$ mg Betamethason vor und bis Tag 8 der Therapie mit DEC. DEC führt zu einem Absterben von ca. $50 \%$ der adulten Würmer; unklar ist, warum die überlebenden Würmer nach einer erneuten DEC-Therapie nicht absterben.

In jüngerer Zeit hat sich gezeigt, dass $W$. bancrofti intrazelluläre Bakterien der Gattung Wolbachia beherbergt, die seit Millionen von Jahren eine Symbiose mit den Filarien eingegangen sind. Eine Depletion von Wolbachia mit Doxycyclin führt in über $85 \%$ zum Absterben der Würmer. Die derzeitige Dosierung beträgt $200 \mathrm{mg}$ Doxycyclin täglich für 4 Wochen. Wegen der besseren Wirkung sollte Doxycyclin, wenn eine Gabe von 4 Wochen verlässlich durchgeführt werden kann, vor DEC der Vorzug gegeben werden. Da die Würmer unter Doxycyclin nur langsam absterben, kommt es nicht zu den schmerzhaften knoten im Skrotalbereich, wie bei DEC.

Da Ivermectin nicht makrofilarizid ist, sollte es nur in Kombination mit Doxycyclin bei Mikrofilarien-bedingten Erkrankungen (z. B. TPE) gegeben werden. Gegen Lymphödem sind - neben der nur in Spezialzentren durchzuführenden chirurgischen Behandlung - supportive Maßnahmen (Fuß hochlagern, Fußhygiene, Vermeidung des Eindringens von Erregern durch Hautläsionen) indiziert. Doxycyclin (6 Wochen $200 \mathrm{mg} / \mathrm{d}$, ein Zyklus pro Jahr) führt zu einer weiteren Verbesserung mit Aufhalten der Progredienz bei frühen Stadien. Dieses Schema ist auch bei kleinen Hydrozelen wirksam und führt zu einer Volumenreduktion. Größere Hydrozelen sowie Chylozelen müssen dagegen operiert werden.

\section{Resistenz}

Es gibt derzeit keine Hinweise auf Resistenz gegen DEC oder Doxycyclin; Resistenzen gegenüber Ivermectin werden jedoch für möglich gehalten, da es unter Ivermectingabe zu einer Selektion von Genen 
kommt, die im Veterinärbereich verantwortlich für die Resistenz von intestinalen Würmern sind.

\section{Epidemiologie}

\section{Verbreitung}

Die Wuchereriasis ist in den tropischen Regionen Afrikas, Asiens und Amerikas sowie auf verschiedenen südpazifischen Inseln weit verbreitet, wo mehr als 120 Mio. Menschen infiziert sind. Wichtige Vorkommen in Amerika befinden sich in Brasilien und Haiti, Guyana, Costa Rica und Surinam. In Afrika ist neben Ägypten (Nildelta) der gesamte Tropengürtel betroffen, wenn auch mit unterschiedlicher Häufigkeit. Die asiatischen Herde liegen in Indien, Bangladesch, Nepal, Sri Lanka, Myanmar, Malaysia, Indonesien und auf den Philippinen. Im Südpazifik ist W. bancrofti u. a. auf den Fiji-Inseln, auf Samoa, den Cook-Inseln und in Französisch Polynesien endemisch.

\section{Wirtsbereich / Reservoir}

Einziger natürlicher Endwirt von W. bancrofti ist der Mensch. Obwohl sich Affen (Presbytis cristatus) experimentell infizieren lassen, ist ein tierisches Reservoir nicht bekannt.

\section{Risikogruppen}

Voraussetzung für den Erwerb einer Wuchereriasis ist der Aufenthalt in einem Endemiegebiet mit zusätzlicher Mückenexposition. Besonders gefährdet ist die ländliche, in Gewässernähe lebende Bevölkerung der Endemiegebiete, da die Larven- und Puppenentwick- lung der Überträger an das Wasser gebunden ist. Allerdings ist die Übertragung weitaus weniger effizient als z. B. die von Plasmodien durch Anopheles; mehrere 100 Stiche infizierter Mücken sind statistisch nötig, bis sich eine Infektion etabliert. Deswegen sind Touristen ohne besondere Exposition (längerer Aufenthalt in einem Endemiegebiet ohne Schutzmöglichkeiten) normalerweise nicht gefährdet. Im 2. Weltkrieg haben sich viele amerikanische und britische Soldaten in den Endemiegebieten im Pazifik infiziert, was zu einer vorübergehenden Steigerung der Forschungsbudgets durch die entsprechenden Regierungen geführt hat.

\section{Transmission / Vektoren}

Die Übertragung von W. bancrofti erfolgt ausschließlich durch Stechmücken der Gattungen Culex, Aedes, Anopheles und Mansonia, deren Aktivitätsphasen weitgehend mit dem rhythmischen Auftreten der Mikrofilarien im peripheren Blut zusammenfallen. Periodische oder sub- bzw. semiperiodische Präsenz ist vom Endemiegebiet und den jeweiligen Überträgern abhängig. Bei ausgeprägter Periodizität, die am weitesten verbreitet ist, treten Mikrofilarien ausschließlich nachts oder in den späten Abendstunden im Blut auf, bei Subperiodizität auch tagsüber.

\section{Prävention / Impfstoffe}

Schutz vor Mückenstichen durch Anwendung von Repellentien und Moskitonetzen sowie geeignete Kleidung kann die Übertragung von infektiösen Larven verhindern. Es ist außerdem aus verschiedenen Tier-

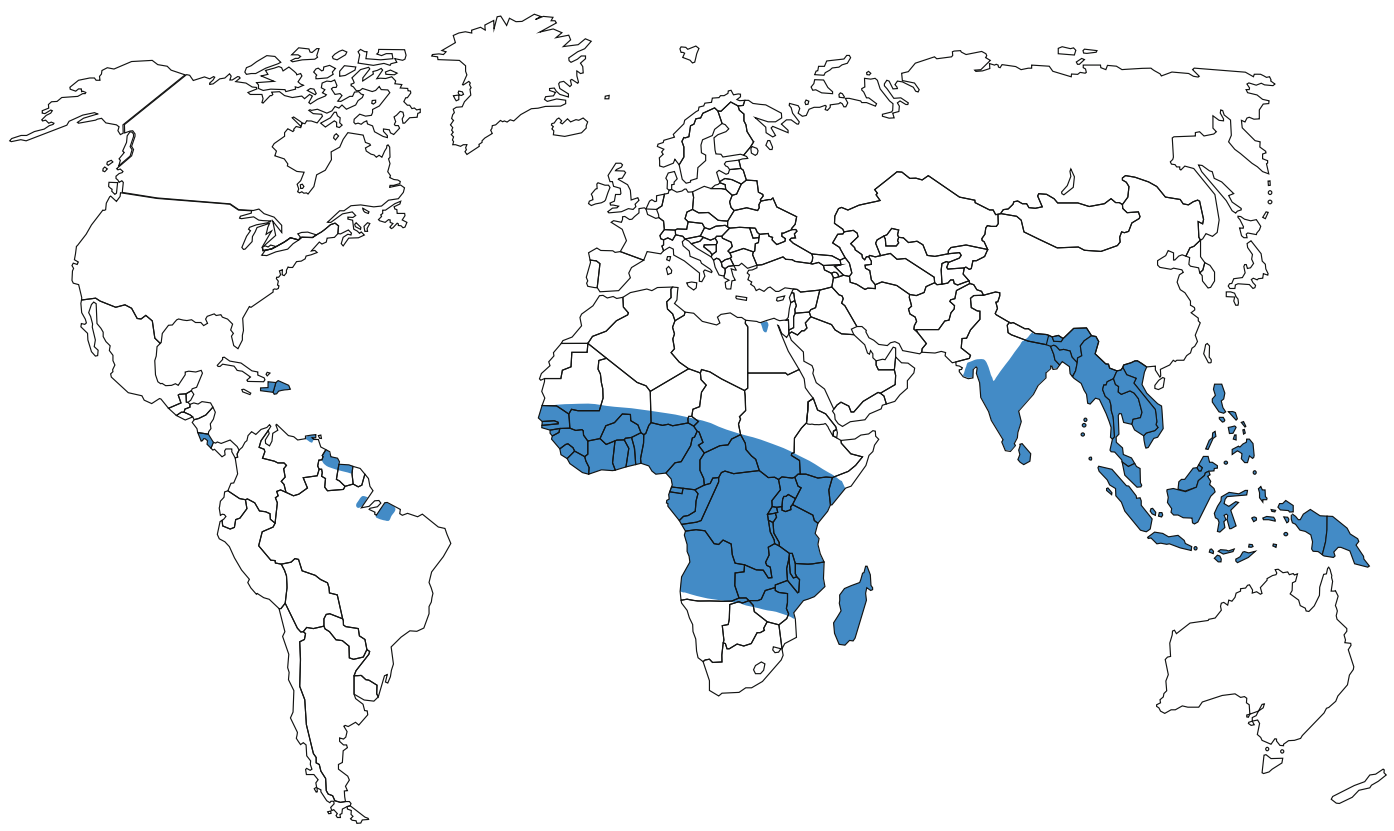


modellen bekannt, dass die Chemotherapeutika Ivermectin und Doxycyclin die Reifung von infektiösen Larven zu adulten Würmern verhindern können. Eine Malariaprophylaxe mit Doxycyclin verhindert also mit großer Wahrscheinlichkeit auch eine Infektion mit W. bancrofti.

\section{Ausbruchsmanagement}

Plötzliche Ausbrüche kommen nicht vor. Generell wird versucht, die Transmission von Filariosen durch Massenchemotherapie mit mikrofilariziden Substanzen zu verhindern. Die „Global Alliance for the Elimination of Lymphatic Filariasis" ist ein Zusammenschluss wichtiger privater und öffentlicher Geldgeber unter der Führung der WHO mit dem Ziel, die Prävalenz der Lymphatischen Wuchereriasis unter ein Niveau zu drücken, bei dem sie kein Problem der öffentlichen Gesundheit mehr darstellt $(<1 \%$ in allen Verwaltungsdistrikten der entsprechenden Länder). Dies soll durch folgende Massenchemotherapieschemata erreicht werden:

- In Ländern außerhalb Afrikas: Diäthylcarbamazin (DEC; $6 \mathrm{mg} / \mathrm{kg} \mathrm{KG)}$ plus Albendazol (400 mg). Eine pharmakologisch synergistische Wirkung ist nicht gesichert, jedoch erhöht die Gabe von Albendazol durch die Elimination der intestinalen Würmer, die von den Patienten bemerkt wird, die Compliance.

- In Afrika: Ivermectin plus Albendazol; wegen der oft gleichzeitig vorliegenden Onchozerkose darf kein DEC gegeben werden, weil DEC bei Onchozerkose durch die Abtötung von Mikrofilarien im Auge bleibende Schäden hinterlassen kann.

\section{Meldepflicht}

Keine.

\section{Weiterführende Informationen}

\section{Referenzzentren / Expertenlaboratorien}

- Das Bernhard-Nocht-Institut für Tropenmedizin in Hamburg ist Referenzzentrum der Dt. Gesellschaft f. Hygiene u. Mikrobiologie (DGHM) für alle tropischen Erreger; als fachlich qualifiziert anzusehen sind aber sämtliche parasitologischen und tropenmedizinischen Institutionen.

\section{Web-Adressen}

- The Institute for Genomic Research: http://www.tigr.org/

- Wellcome Trust Sanger Institute for Genome Sequencing: http://www.sanger.ac.uk/Projects/Helminths/

- Nematoden-Genomseite der Universität Edinburgh: www.nematodes.org/

- CDC-Center for Disease Control and Prevention: http:// www.cdc.gov/ncidod/dpd/parasites/lymphaticfilariasis/ index.htm

- WHO-World Health Organization: http://www.who.int/ topics/filariasis/en/

\section{Schlüsselliteratur}

1. Debrah AY, Mand S, Specht S, Marfo-Debrekyei Y, Batsa L,
Pfarr K, Larbi J, Lawson B, Taylor M, Adjei O, Hoerauf A (2006) Doxycycline reduces plasma VEGF-C/sVEGFR-3 and improves pathology in lymphatic filariasis. PLOS Pathogens 2 (9):e92

2. Hoerauf A (2008) Filariasis: new drugs and new opportunities for lymphatic filariasis and onchocerciasis. Curr Opin Infect Dis 21:673-681

3. Löscher T, Burchard G (Hrsg) (2010) Tropenmedizin in Klinik und Praxis. 4. Aufl. Georg Thieme Verlag, Stuttgart New York

4. Lucius, R. \& Loos-Frank, B. (2008) Biologie von Parasiten. 552 pages. Springer-Verlag Berlin, Heidelberg, New York.

5. Nutman TB (ed) (2000) Lymphatic filariasis. Tropical Medicine: Science and Practice, vol 1. Imperial College Press, London

6. Taylor MJ, Makunde WH, McGarry HF, Turner JD, Mand S, Hoerauf A (2005) Macrofilaricidal activity following Doxycycline treatment of Wuchereria bancrofti: a doubleblind randomised controlled trial. Lancet 365:2116-2121

7. WHO Expert Committee on Filariasis (1992) Lymphatic filariasis: the disease and its control. Fifth report of the WHO Expert Committee on Filariasis. WHO Tech Rep Ser 821

8. WHO Model Prescribing Information (1995) Drugs used in parasitic diseases. 2nd Ed. World Health Organization, Geneva; kann unter der Website http://apps.who.int/ medicinedocs/en/d/Jh2922e/ kostenlos heruntergeladen werden!

\section{Wundbotulismus}

- Clostridium botulinum

\section{Wundinfektion}

- Acinetobacter

- Aggregatibacter

- Alcaligenes/Achromobacter

- Bacillus-Arten (fakultativ bzw. opportunistisch pathogen)

- Bacteroides

- Burkholderia, Ralstonia

- Capnocytophaga

- Citrobacter

- Clostridien der Gasbrandgruppe

- Clostridium botulinum

- Corynebacterium, sonstige Spezies

$\checkmark$ Eikenella

- Enterobacter

- Enterokokken

- Escherichia coli

- Eubakterien

- Flavobacterium

- Hafnia

$\checkmark$ Klebsiella

- Moraxella catarrhalis

- Nocardia

- Pasteurella multocida

- Propionibakterien 
Proteus mirabilis, Proteus vulgaris

Prototheca wickerhamii

- Providencia, Morganella

- Pseudomonas

- Serratia

- Staphylococcus aureus

- Streptobacillus

Vibrio

\section{Wundinfektion nach Tierbiss}

- Capnocytophaga

- Pasteurella multocida

\section{Wundstarrkrampf}

-Clostridium tetani

\section{Wundstarrkrampf-Erreger}

Clostridium tetani

\section{WU-Polyomavirus}

Polyomaviren

\section{Wüstenfieber}

Coxiellen

\section{Wüstengrippe}

- Coccidioides immitis

\section{Wyeomyia-Virus}

Bunyaviren 


\section{$\mathbf{X}$}

Xenopsylla cheopis

- Ektoparasiten, sonstige (Stechmücken, Trombiculiden, Flöhe, Wanzen, Zecken)

\section{Xingu-Virus}

Bunyaviren

\section{X-linked Lymphoproliferative Disease}

- Epstein-Barr-Virus 


\section{Yatapockenvirus}

- Pockenviren, zoonotische

\section{Yersinia pestis}

- Yersinien

\section{Yersinien}

\section{Erreger}

JÜrgen HeEsemanN

\section{Synonym(e)}

Pesterreger (Yersinia pestis), Yersinien.

\section{Erregerspezies}

Yersinia pestis, Y. pseudotuberculosis, Y. enterocolitica.

\section{Taxonomie}

Abteilung: Proteobacteria; Unterabteilung: GammaSubklasse; Familie: Enterobacteriaceae; Gattung: Yersinia

Arten: Y. pestis, Y. pseudotuberculosis, Y. enterocolitica, Y. intermedia, Y. frederiksenii, Y. kristensenii, Y. aldovae, Y. rohdei, Y. mollaretii, Y. bercovieri, Y. ruckeri

\section{Historie}

Y. pestis ist der Erreger der Pest. Drei Pest-Pandemien sind historisch belegt:

1. Pandemie im 6. Jahrhundert (Mittelmeerraum),

2. Pandemie ab 1347 in Europa,

3. Pandemie ab 1860 von China ausgehende Verbreitung bis nach Afrika und Amerika.

Es gilt als gesichert, dass A. Yersin und nicht S. Kitasato den Pesterreger 1894 in Hongkong entdeckt hat. Der Japaner M. Ogata konnte 1897 nachweisen, dass Flöhe sich an pesterkrankten Ratten infizieren und den Pesterreger auf Tiere und Menschen übertragen können.

Y. pseudotuberculosis wurde 1889 von Pfeiffer isoliert, charakterisiert und als Bacillus pseudotuberculosis rodentium (Erreger der Meerschweinchen-Pseudotuberkulose) benannt. Erst 1954 konnte von Knapp und Masshoff der ätiologische Zusammenhang zwischen der beim Menschen beschriebenen retikulozytär abszedierenden mesenterialen Lymphadenitis und Y. pseudotuberculosis (damals Pasteurella pseudotuberculosis) aufgezeigt werden.
Y. enterocolitica ist wahrscheinlich 1938 zuerst von Schleifstein und Colemann als humaner Infektionserreger beschrieben worden (Bacterium enterocoliticum). Aufgrund der Heterogenität dieser Erregerart wurde sie zunächst Pasteurella $\mathrm{X}$ genannt und der Gattung Pasteurella zugeordnet. Erst 1965 wurde der Gattungsname Yersinia und die Zuordnung zur Familie Enterobacteriaceae festgelegt.

\section{Morphologie}

Yersinien erscheinen mikroskopisch als kurze gramnegative Stäbchen. Nach Methylenblau- oder WaysonAnfärbung erscheint $Y$. pestis sicherheitsnadelförmig (bipolares Stächen). Y. enterocolitica und Y. pseudotuberculosis sind bei $28^{\circ} \mathrm{C}$ Bebrütung begeißelt. Y. pestis ist grundsätzlich unbeweglich.

\section{Genom}

Die Genome von Y. pestis, Y. pseudotuberculosis und $Y$. enterocolitica sind vollständig sequenziert (Genomgröße 4,65 bzw. 4,62 Megabasenpaare, GC-Gehalt: 47,3 \%). Ein Vergleich der Genome zeigt, dass Y. pestis aus Y. pseudotuberculosis Serotyp I hervorgegangen ist.

\section{Vermehrung}

Vermehrung bei Temperaturen zwischen 0 und $4{ }^{\circ} \mathrm{C}$ ist für die psychrophilen Y. enterocolitica und Y. pseudotuberculosis typisch. Die optimale Vermehrungstemperatur der humanpathogenen Yersinien liegt bei $26-28^{\circ} \mathrm{C}$. Im infizierten Wirt vermehren sich die Erreger vorwiegend extrazellulär. Die biochemischen und mikrobiologischen Merkmale sind in $\mathbf{T a b}$. 1 zusammengefasst.

\section{Pathogenität / Virulenz / Antigenvariabilität}

Die pathogenen Eigenschaften der Yersinien werden seit 1980 molekularbiologisch untersucht. Die wichtigsten Pathogenitätsfaktoren werden von Plasmiden determiniert, wobei ein 70 Kilobasen (kb)-großes Virulenzplasmid (pYV) bei allen drei humanpathogenen Yersinien vorkommt. Es befähigt die Yersinien nach Kontakt mit Wirtszellen, Proteine (Yersinia outer proteins: Yops) in die Zellen einzuschleusen (polarisierte Translokation, Typ 3 Proteinsekretionssystem) und diese funktionell auszuschalten (Unterdrückung der Phagozytose und der Sauerstoffradikalbildung bei Makrophagen und Neutrophilen z. B. durch die Proteintyrosinphosphatase, YopH). Diese Strategie ermöglicht den Yersinien das extrazelluläre Überleben im Wirt. Im Gegensatz zu den enteropathogenen Yersinien trägt $Y$. pestis noch zusätzlich ein $10 \mathrm{~kb}$ und ein 
Tab. 1. Wichtige Differenzierungsmerkmale der verschiedenen Yersinia-Arten.

\begin{tabular}{|l|l|l|l|l|l|l|}
\hline Art & $\begin{array}{l}\text { Beweg- } \\
\text { lichkeit } \\
\mathbf{2 8} \mathbf{~}^{\circ} \mathrm{C}\end{array}$ & Ornithin & $\begin{array}{l}\text { Saccha- } \\
\text { rose }\end{array}$ & Äskulin & Melibiose & $\begin{array}{l}\text { Calcium- } \\
\text { abhängiges } \\
\text { Wachstum, } \\
37^{\circ} \mathrm{C}\end{array}$ \\
\hline Y. pestis & - & - & - & - & $+/-$ & + \\
\hline Y. pseudotuberculosis & + & - & - & + & + & + \\
\hline $\begin{array}{l}\text { Y.enterocolitica } \\
\text { Biovar 1B-5 }\end{array}$ & + & + & + & - & - & + \\
\hline Biovar 1A (apathogen) & + & + & + & + & - & - \\
\hline Y. intermedia & + & + & + & + & + & - \\
\hline Y. frederiksenii & + & + & + & + & - & - \\
\hline Y. kristensenii & + & + & - & - & - & - \\
\hline
\end{tabular}

100 kb Plasmid, die ebenfalls Virulenzfaktoren (Plasminaktivator bzw. Fraktion 1-Kapsel) determinieren. Dagegen exprimieren ausschließlich enteropathogene Yersinien ein chromosomales Invasionsgen (inv) und ein plasmidkodiertes Adhäsions-/Kolonisierungsgen (yadA). Diese Pathogenitätsgene haben für die molekularbiologische Diagnostik Bedeutung gewonnen. Virulenzassoziierte Merkmale sind bei $Y$. pestis die Pigmentation der Kolonien auf Blutagar aufgrund der Hämin-Speicherung. Die Wachstumsinhibition bei $37^{\circ} \mathrm{C}$ im kalziumfreien Nährmedium ist typisch für alle drei humanpathogenen Yersinia-Arten, die das Virulenzplasmid pYV tragen.

\section{Erkrankungen}

\section{Beulenpest, Lungenpest, Pestsepsis}

\section{Synonym(e)}

Bubonenpest, Pest, „Schwarzer Tod“.

\section{Inkubationszeit}

Die Inkubationszeit bei $Y$. pestis beträgt in der Regel 5-7 Tage nach dem Flohbiss. Nach Übertragung durch Aerosole von Lungenpestpatienten kann die Inkubationszeit 1-2 Tage dauern.

\section{Leitsymptome}

Lymphknotenschwellung, Fieber, Kopfschmerzen, blutiger Auswurf bei Lungenpest.

\section{Symptome}

Y. pestis ist der Erreger der Beulen- und Lungenpest. Die vom Flohbiss aus proximal gelegenen Lymphknoten (untere Extremitäten: Inguinallymphknoten, obere Extremitäten: axilläre Lymphknoten) werden infiziert und schwellen zu schmerzhaften Beulen (Bubonenpest) bis zum Aufplatzen an (5-7 Tage nach Floh- biss). Der Lymphknotenschwellung gehen uncharakteristische Symptome wie Übelkeit, Erbrechen, Durchfall und Fieber voraus. Aus der Bubonenpest kann sich eine letale Pestsepsis mit gangrösen Hautnekrosen („Schwarzer Tod“) entwickeln (10-15\% der Fälle). Die Lungenpest (Pestpneumonie) ist hoch infektiös (Tröpfchen) und verläuft in 1-3 Tagen nach Infektion in 50-90\% der Fälle tödlich.

\section{Pathophysiologie}

Nach Übertragung des Pesterregers durch Flohbiss wird der Erreger wahrscheinlich über Lymphgefäße in den nächstgelegenen Lymphknoten transportiert, wo er sich extrazellulär schnell zu einer eitrigen Masse vermehrt. Die Erreger können auch in die Blutbahn gelangen und eine Pestsepsis verursachen. Das Typ-3Proteinsekretionssystem (Mikroinjektion von Effektorproteinen $=$ Yops) schützt die Erreger vor Phagozytose. Wahrscheinlich hat das kurzkettige Lipopolysaccharid eine hohe Endotoxinaktivität und beeinträchtigt auch das Blutgerinnungssystem. Ein spezifisches Exotoxin ist nicht bekannt.

\section{Immunantwort}

Wegen des akuten Verlaufs der Pest haben serologische Verfahren für die Diagnostik nur retrospektive Bedeutung. Antikörper können gegen das Kapselprotein Fraktion 1 und gegen das V-Antigen nachgewiesen werden

\section{Differenzialdiagnose}

Lymphadenitis bei Yersiniose, Epstein-Barr-Virus Infektion (EBV), Toxoplasmose, Staphylokokken/Streptokokken-Infektionen, Syphilis, Lymphogranuloma venereum, Ulcus molle, Pneumonie bei Tularämie, Psittakose, Q-Fieber, Mycoplasma pneumoniae-Infektion, virale Pneumonien. 


\section{Yersinia-pseudotuberculosis-Infektion, Yersinia-enterocolitica-Infektion}

\section{Synonym(e)}

Yersiniose.

\section{Inkubationszeit}

Je nach oral aufgenommener Dosis 1-5 Tage.

\section{Leitsymptome}

Fieber, gastroenteritische Beschwerden.

\section{Symptome}

Y. pseudotuberculosis und Y. enterocolitica (enteropathogene Yersinien) verursachen nach oraler Aufnahme in der Regel intestinale Infektionen (Yersiniosen). Die klinischen Manifestationen sind vielfältig und hängen vom Erreger, der Infektionsdosis, dem Infektionsort und der Vorgeschichte des Patienten ab. Eine Yersiniose bei Säuglingen und Kleinkindern manifestiert sich in der Regel als eine einwöchige Gastroenteritis mit Fieber, wässrigem oder leicht blutigem Durchfall und Erbrechen. Schulkinder und Jugendliche entwickeln häufiger eine leichte Gastroenteritis mit Betonung von Schmerzen im rechten Unterbauch (Pseudoappendizitis) aufgrund einer mesenterialen Lymphadenitis und/oder terminalen Ileitis. Auch in diesen Fällen heilt die fieberhafte Erkrankung nach 1-2 Wochen komplikationslos aus. Beim Erwachsenen werden sehr uncharakteristische Krankheitsbilder bei Yersiniose beschrieben: Pharyngitis, abdominale Schmerzen, Fieber, Myalgien, Symptome eines grippalen Infektes, Morbus Crohn ähnliche Symptome (chronisch-rezidivierende Ileokolitis). Infektionen mit enteropathogenen Yersinien können bei Jugendlichen und gehäufter noch bei Erwachsenen (insbesondere HLA-B27-Trägern) nach zwei bis drei Wochen zu so genannten reaktiven oder infektallergischen Erkrankungen wie reaktive Arthritis, Erythema nodosum, Thyreoiditis, Uveitis, Sweet-Syndrom, Guillain-BarrèSyndrom u. a. führen. Patienten mit Abwehrschwäche (hohes Alter, Diabetes mellitus, Leberzirrhose, Leukämie, hämolytische Anämie, insbesondere Thalassämie u. a.) können extraintestinale Yersinien-Infektionen entwickeln (multiple Leberabszesse, Pleuritis, Perikarditis, Meningitis, Osteomyelitis, Septikämie u. a.). Y. enterocolitica gehört zu den häufigsten durch Bluttransfusion übertragenen gramnegativen Sepsis-Erregern.

\section{Pathophysiologie}

Nach oraler Aufnahme und Dünndarmpassage gelangen die Erreger zur besonders strukturierten Mukosader Peyer-Plaques (domförmig). Dort werden die Erreger wahrscheinlich über die M-Zellen in die Lymphfollikel transportiert, wo sie sich extrazellulär vermehren und bis zu den mesenterialen Lymphknoten vordringen. Der Durchfall bei Y. enterocolitica ist wahrscheinlich auf das hitzestabile Enterotoxin (ST) zurückzuführen, das die Guanylcyclase stimuliert. $Y$. pseudotuberculosis ist ST-negativ und verursacht selten Durchfall. Histologisch zeigt sich bei Y. pseudotuberculosis eine typische mesenteriale retikulozytäre abszedierende Lymphadenitis.

\section{Immunantwort}

Eine Yersiniose führt zur klassenspezifischen Serumantikörperantwort (IgM, IgA, IgG) gegen O-Antigen und Virulenzplasmid kodierte Proteine (Yersinia outer protein: YopE, D, B, H, M) und gegen das V-Antigen.

\section{Differenzialdiagnose}

Differenzialdiagnostisch sind Erkrankungen mit gleicher klinischer Symptomatik, die durch darmpathogene Erreger hervorgerufen werden, zu berücksichtigen (z. B. Salmonellose, Campylobakteriose, darmpathogene Escherichia coli, Enteroviren, Amöben). Bei chronisch-rezidivierenden Verläufen ist an Morbus Crohn zu denken.

\section{Diagnostik}

\section{Untersuchungsmaterial}

Y. pestis: Buboneneiter/Punktat, Blut und Sputum, Rachenabstrich.

Y. pseudotuberculosis, Y. enterocolitica: Stuhlproben, Rektalabstrich, Blut, Rachenabstrich.

\section{Diagnostische Verfahren}

\section{Kulturelle Diagnostik}

Pest: Der Pesterreger kann aus Buboneneiter (Bubonenaspirat) leicht auf Blutagar angezüchtet (Wachstum bei $28^{\circ} \mathrm{C}$ über 48 Stunden) oder nach Ausstrich und Färbung mit Methylenblau nach Gram oder Wayson mikroskopisch identifiziert werden. Zum Direktnachweis und zur weiteren Differenzierung ist eine Immunfärbung mit Antiserum gegen das Y. pestis spezifische Fraktion 1(F1)-Kapselantigen erforderlich. Die serologische Diagnostik ist nur mit Konvaleszentenseren lohnend und deshalb von untergeordneter Bedeutung. Eine O-Serotypisierung von Y. pestis ist nicht möglich (kurzkettiges Lipopolysaccharid ohne O-spezifische Seitenkette). Die Pesterreger können in die drei Biogruppen antiqua, medievalis und orientalis unterteilt werden. Die mikrobiologische Diagnostik der Pest (Anzucht und Differenzierung des Erregers) sollte aufgrund der Gefährlichkeit des Erregers zugelassenen Laboratorien (Sicherheitsstufe L-3) vorbehalten bleiben.

Yersiniose: Infektionen mit enteropathogenen Yersinien werden mikrobiologisch (Erregeranzucht) und serologisch diagnostiziert. Bei Verdacht auf intestinale Yersinien-Infektion können die Erreger aus Stuhlkulturen angezüchtet werden (MacConkey-Agar, Salmonella-Shigella-Agar, Cefsulidin-Irgasan-Novobiocin (CIN)-Agar). Wichtig ist die Einhaltung der Bebrütungsdauer (24-48 Stunden) und der Temperatur 
$\left(22-28^{\circ} \mathrm{C}\right)$. Es ist empfehlenswert, parallel eine Stuhlprobe in einer Kälteanreicherung (phosphatgepufferte Kochsalzlösung, 3 Wochen, $4{ }^{\circ} \mathrm{C}$ ) mitzuführen und wöchentlich Proben auf CIN-Agar zu subkultivieren. Die Anzucht von Y. pseudotuberculosis aus Stuhlproben gelingt viel seltener als die von $Y$. enterocolitica. Am häufigsten werden $Y$. pseudotuberculosis aus mesenterialen Lymphknoten und Blutkulturen isoliert. Bei der Kälteanreicherung werden häufig nicht pathogene Yersinien isoliert (apathogene Y. enterocolitica und andere Yersinia-Arten). Verdächtige Kolonien müssen deshalb sorgfältig biochemisch differenziert und anschließend biotypisiert (Biotypen IA, IB, II-V) sowie mit $\mathrm{O}$-antigenspezifischen Seren serotypisiert werden $(\triangleright$ Tab. 1$)$. Serotypisierungen nach $\mathrm{H}$-Antigen und Virulenzantigen (Yersinia-Adhäsin, YadA) bleiben in der Regel Expertenlabors vorbehalten. Die häufigsten humanpathogenen $Y$. enterocolitica-Isolate in Europa gehören den Serotypen/Biotypen 03/IV, 09/II und $05.27 / \mathrm{II}$ an, in Nordamerika werden zusätzlich auch Biotyp IB-Stämme der Serotypen 08, 013, 020 und 021 als Erreger beim Menschen isoliert (sehr selten in Europa!). Y. enterocolitica der Serotypen 09 und 05.27 können in seltenen Fällen auch dem Biotyp III zugeordnet werden. Y. enterocolitica-Isolate des Biotyps IA (über 40 verschiedene Serotypen) werden als nicht enteropathogen angesehen. Bei humanpathogenen Y. pseudotuberculosis-Isolaten konnten bisher 10 Hauptserotypen und zahlreiche Subserotypen (A, B) definiert werden. In Deutschland werden in der Regel die Serotypen I, II und III isoliert. Die Serotypisierung von enteropathogenen Yersinien muss aufgrund der zahlreichen Kreuzreaktivitäten mit unterschiedlichen Yersinia-Arten, Salmonellen, Escherichia coli und Brucellen kritisch bewertet werden. Für die Schnelldiagnostik stehen spezifische molekularbiologische Verfahren (PCR) zur Verfügung. Y. pestis kann auch mit spezifischem Antiserum (Anti-F1-Serum) mittels indirekter Immunfluoreszenz im Sputum oder Punktat nachgewiesen werden.

\section{Serologische Diagnostik}

Yersiniosen können mit üblichen serologischen Techniken wie Widal-Agglutination, KBR und ELISA diagnostiziert werden. Da Oberflächenantigene der Erreger hierbei zum spezifischen Antikörpernachweis verwendet werden, müssen die häufigsten Serotypen berücksichtigt werden (z. B. für Europa: Y. enterocolitica 03, 09, 05,27 und Y. pseudotuberculosis I, II und III). Sensitivität und Spezifität dieser Tests sind nicht zufriedenstellend.

Neuerdings werden auch virulenzassoziierte Antigene, die allen humanpathogenen Yersinien gemeinsam sind, im Immunblot und ELISA verwendet. Bei diesen Antigenen handelt es sich um plasmidkodierte sezernierte Proteine (YopD, E, H, M und V-Antigen). Für eine akute oder vor kurzer Zeit durchgemachte Yersiniose sprechen positive IgG-, IgA- und ggf. IgM-Titer.
Der Test erfasst alle Infektionen mit humanpathogenen Yersinien in einem Testsystem (serotyp-und speziesunabhängig). Spezifische IgA-Serumantikörper sind bis zu einem Jahr nach Infektion nachweisbar.

\section{Befund / Interpretation}

Die Anzucht des Erregers erlaubt eine eindeutige Diagnose (bei Y. enterocolitica Sero- und Biotypisierung erforderlich). Serologische Befunde können nur Hinweise ergeben und müssen zusammen mit dem Krankheitsbild (z. B. reaktive Arthritis und positiver Nachweis von Yop-spezifischen IgG- und IgA-Antikörpern) interpretiert werden. Widal-Agglutinationstiter bei Y. enterocolitica Serotyp O9 müssen wegen der Kreuzreaktivität mit Brucellen-O-Antigen weiter abgeklärt werden.

\section{Therapie}

\section{Therapeutische Maßnahmen}

Pest: Bisher wurde zur Therapie empfohlen: Streptomycin (30 mg/kg KG/d über 3 Tage) mit anschließender Tetrazyklin-Therapie (8 Tage). Alternativ haben sich auch Chloramphenicol oder Fluorochinolone als empfehlenswert erwiesen.

Yersiniose: Akute intestinale Yersinia-Infektionen erfordern keine Antibiotikatherapie. Extraintestinale Infektionen (z. B. Leberabszesse) und Yersinia-Septikämien sprechen gut auf Gyrasehemmer oder Drittgenerations-Cephalosporine plus Aminoglykosid an. Die Indikation der Antibiotikatherapie (z. B. mit Tetrazyklin, TMZ, Ciprofloxacin) bei postinfektiösen Yersinia-Erkrankungen (z. B. bei reaktiver Arthritis) wird kontrovers diskutiert.

\section{Resistenz}

Bis vor wenigen Jahren waren Resistenzen gegen übliche Antibiotika bei Y. pestis nicht bekannt. 1997 wurde erstmalig ein multiresistentes $Y$.-pestis-Patientenisolat in Madagaskar beschrieben (Resistenzen gegen Ampicillin, Chloramphenicol, Kanamycin, Streptomycin, Spectinomycin, Sulfonamid und Tetrazyklin).

Die europäischen Y.-enterocolitica-Serotypen 03, 09 und 05.27 sind grundsätzlich resistent gegen Ampicillin und Cephalosporine der 1. und 2. Generation und in der Regel empfindlich auf Tetrazyklin, Aminoglykoside, Drittgenerations-Cephalosporine, Fluorochinolone und Trimethoprim-Sulfmethoxazol (TMZ).

\section{Epidemiologie}

\section{Verbreitung}

Yersinia-Infektionen gehören zu den Anthropozoonosen. Y. pestis kommt endemisch bei Wildnagetieren (Ratten, Erdhörnchen etc.) in den USA, Südamerika, Südafrika, Madagaskar, im Mittleren Osten, in Kasachstan, China, der Mongolei, Vietnam, Indien u. a. vor. Infizierte Flöhe können praktisch alle Säugetierarten infizieren. Es gibt Y.-pestis-resistente Nagetierarten. 
Y. pseudotuberculosis kommt endemisch bei Wildnagetieren vor (z. B. in Japan). Auch bei Wildvögeln, Wassergeflügel und in Gewässern konnte Y. pseudotuberculosis isoliert werden. Dieses Reservoir führt wahrscheinlich zur Kontamination von Nahrungsmitteln.

Y. enterocolitica der Biotypen II-IV kommen im Wesentlichen bei Schlachtschweinen vor (Tonsillen, Darm, Zunge), aber auch Haustiere können latent infiziert sein. Biotyp III- und V-Yersinien haben gehäuft $\mathrm{zu}$ Infektionen bei Nerzen und Chinchillas in Pelztierfarmen sowie Wildhasen geführt, selten dagegen beim Menschen.

Y. enterocolitica Biotyp IB kommen gehäuft bei Wildnagetieren, Füchsen und Waschbären sowie in Gewässern der USA und neuerdings auch in Deutschland vor.

\section{Wirtsbereich / Reservoir}

Y. pestis: alle Säugetierarten.

Y. pseudotuberculosis: Nagetiere, Vögel, Geflügel, Nutztiere, Mensch.

Y. enterocolitica: Nagetiere, Nerz, Chinchilla, Haustiere, Schwein, Mensch.

\section{Risikogruppen}

Für Y. pestis besteht keine Prädisposition beim Menschen. Zur Risikogruppe gehören Jäger, Fallensteller, Wanderer u. a. in Pestgebieten ( $\triangleright$ Epidemiologie). Für Y. enterocolitica und Y. pseudotuberculosis sind besonders Kleinkinder empfänglich. Postinfektiöse Erkrankungen wie reaktive Arthritis nach Yersiniose verlaufen besonders schwer und rezidivierend bei HLAB27-Trägern. Abwehrschwäche, hämolytische Anämie, Leberzirrhose, Thalassämie und Desferal'-Therapie sind Risikofaktoren für die Yersinia-Sepsis und andere extraintestinale Infektionen.

\section{Transmission / Vektoren}

Y. pestis wird durch infizierte Flöhe übertragen, die von Nagetieren aus Wildpestherden stammen, oder von Haustieren, die mit infizierten Wildnagetieren Kontakt hatten. Bei Vorkommen von Lungenpest spielt die Tröpfchenübertragung von Mensch zu Mensch eine wichtige Rolle.

$Y$. enterocolitica und $Y$. pseudotuberculosis werden durch kontaminierte Nahrungsmittel (häufig rohes Schweinefleisch, Innereien, Milch, Wasser u. a.) aufgenommen (oral-alimentär). Auch infizierte Haustiere und Zootiere können zur Infektionsquelle (insbesondere Kontaktinfektionen mit Y. pseudotuberculosis) werden.

\section{Prävention / Impfstoffe}

$Y$. pestis-Infektionen können verhütet werden durch Meidung von Pestherden ( $\triangleright$ Epidemiologie) (Pestherdkontrolle). Eine aktive Impfung ist möglich. Prophylaktisch können Antibiotika eingenommen werden (z. B. TMZ oder Fluorochinolone).
Y. enterocolitica und Y. pseudotuberculosis-Infektionen können durch entsprechenden Hygienestandard in der Lebensmittelherstellung und Tierhaltung erreicht werden. Eine Impfung gibt es bisher nicht.

\section{Ausbruchsmanagement}

Zur Verhütung der Pest steht die Kontrolle der Ausbreitung von Ratten im Vordergrund; bei Infektionen durch enteropathogene Yersinien die Vermeidung des Genusses von kontaminierten Nahrungsmitteln (z. B. rohes Schweinefleisch). Yersinia-pestis-Pneumonie ist als hoch infektiöse Erkrankung der Risikogruppe L3 einzustufen und bei Kontakt ist entsprechende Vorsorge zu treffen. Die wirksamste Maßnahme ist die Antibiotikaprophylaxe mit Trimethoprim-Sulfamethoxazol, Doxycyclin oder Fluorochinolonen.

\section{Meldepflicht}

Nach dem IfSG ist der Verdacht, die Erkrankung und der Tod sowie der Nachweis von Y. pestis meldepflichtig. Erkrankungen durch enteropathogene Yersinien sind ebenfalls meldepflichtig.

\section{Weiterführende Informationen}

\section{Referenzzentren / Expertenlaboratorien}

- Für enteropathogene Yersinien ist zuständig: das Nationale Referenzzentrum für Salmonellen und bakterielle Enteritiserreger, Robert Koch-Institut (Bereich Wernigerode), FB Bakteriologie, Mykologie, Parasitologie, Burgstraße 37, 38855 Wernigerode, E-Mail: tschaepeh@rki.de.

- Besondere Erfahrungen mit Yersinia pestis hat das Laboratoire des Yersinia, Institute Pasteur, 25 et 28, Rue du Docteur-Roux, F-75724 Paris-Cedex 15.

- Die mikrobiologische und serologische Diagnostik der Pest sowie die Biotypisierung von Pesterregern wird auch vom Max von Pettenkofer-Institut für Hygiene und Medizinische Mikrobiologie, Pettenkoferstr. 9a, 80336 München, E-Mail: heesemann@mvp.uni-muenchen.de, durchgeführt (Konsiliarlabor des Robert-Koch-Instituts).

- Weitere Informationen sind über das Robert Koch Institut, Berlin, erhältlich (http://www.rki.de).

\section{Web-Adressen}

- http://www.rki.de

- http://www.pettenkofer-institut.de

\section{Schlüsselliteratur}

1. Aleksic S, Bockemühl J (1990) Mikrobiologie und Epidemiologie der Yersiniosen. Immun Infekt 18:178-185

2. Cover TL, Aber RC (1989) Yersinia enterocolitica. New Engl J Med 321:16-24

3. Galimand M et al. (1997) Multidrug Resistance in Yersinia pestis Mediated by Transferable Plasmid. N Engl J Med 337:677-680

4. Heesemann J (1990) Enteropathogene Yersinien: Pathogenitätsfaktoren und neue diagnostische Methoden. Immun Infekt 18:186-191

5. Heesemann J, Sing A, Trülzsch K (2006) Yersinia's stratagem: targeting innate and adaptive immune defense. Current Opinion in Microbiology 9:55-61 
6. Perry RD, Fetherston JD (1997) Yersinia pestis - Etiologic Agent of Plaque. Clin Microbiol Rev 10:35-66

\section{Yersiniose}

7. Wren BW (2003) The Yersiniae - a model genus to study the rapid evolution of bacterial pathogens. Nat Rev Microbiol 1:55-64

Yersinien 


\section{Zecken}

Ektoparasiten, sonstige (Stechmücken, Trombiculiden, Flöhe, Wanzen, Zecken)

\section{Zeckenbissfieber}

Rickettsien

\section{Zeckenparalyse}

Ektoparasiten, sonstige (Stechmücken, Trombiculiden, Flöhe, Wanzen, Zecken)

\section{Zeckenrückfallfieber}

Borrelien

\section{Zeckenstich}

- Ektoparasiten, sonstige (Stechmücken, Trombiculiden, Flöhe, Wanzen, Zecken)

\section{Zeckentyphus}

Rickettsien

\section{Zerkarien}

\section{Erreger}

Peter Kimmig

\section{Synonym(e)}

Vogelzerkarien, ocellate Furkozerkarien.

\section{Erregerspezies}

Trichobilharzia ocellata, T. franki u. a.

\section{Taxonomie}

Klasse: Trematoda; Ordnung: Strigeida; Familie: Schistosomatidae; Unterfamilie: Bilharziellinae

\section{Historie}

Durch Furkozerkarien verursachte, makulo-papulöse Hautveränderungen wurden erstmals durch Cort 1928 beschrieben. Weitere Darstellungen von Dermatitis verursachenden Zerkarien im Süßwasser erfolgten durch Brumpt 1930, aus marinen Mollusken durch Penner 1950. Umfassende Untersuchungen in Deutschland wurden erstmals durch Neuhaus (1952) und Dönges(1964) vorgenommen.

\section{Morphologie}

Es handelt sich um Zerkarien mit Gabelschwanz (Furkozerkarien), die zwei deutliche Pigmentbecher-Ocellen tragen. Die Gesamtlänge beträgt 600-800 $\mu \mathrm{m}$. Eine Differenzierung der verschiedenen Arten ist auf Zerkarien-Ebene nur molekularbiologisch möglich.

\section{Genom}

Derzeit liegen nur Sequenzen von ribosomalen und mitochondrialen Genen vor, die für den molekularbiologischen Nachweis verwendet werden können. Ein PCR-Produkt vom Genort ToSAU3 lässt sich zur Identifizierung der Gattung Trichobilharzia heranziehen. Die Artdifferenzierung von T. ocellata, T. franki und T. regenti ist durch Sequenzierung dieses Produktes anhand von Punktmutationen möglich.

\section{Vermehrung}

Bei der Zerkariendermatitis handelt es sich um eine Zoonose. Die geschlechtsreifen Saugwürmer leben in der Darmwand und den Darmgefäßen (bei T. regenti in den nasalen Gefäßen) von Wasservögeln, in erster Linie von Enten (Endwirte); ihre Eier gelangen mit dem Kot der Vögel ins Wasser und führen über eine Wimpernlarve (Mirazidium) zur Infektion der Zwischenwirte. Als solche fungieren verschiedene Wasserschnecken-Arten, die spezifisch für die jeweiligen $\mathrm{Pa}$ rasitenarten sind. Die sich hier entwickelnden Larven - die Zerkarien - gelangen ins freie Wasser und suchen die Endwirte auf, in die sie mithilfe histolytischer Drüsensekrete über die Füße eindringen. Über eine Herz-Lungen-Wanderung gelangen sie hier in den Darm, wo sie innerhalb von 2 Wochen zu Adultwürmern heranwachsen.

Aufgrund eines wenig spezifischen Wirtsfindungsvermögens (optische, thermische und chemische Stimuli) können die Zerkarien auch in den Fehlwirt Mensch eindringen, wo sie jedoch bereits in der Haut abgetötet werden.

\section{Pathogenität / Virulenz / Antigenvariabilität}

Über immunologische (Drüsensekrete) und mechanische Reize lösen die Zerkarien in der Haut des Menschen akute Entzündungsreaktionen aus; bei Reinfektionen kommt es zu Sensibilisierung und Verstärkung der Reaktionen. 


\section{Erkrankung}

\section{Zerkariendermatitis}

\section{Synonym(e)}

Badedermatitis, swimmers itch, volkstümlich auch Weiherhibbel oder Hundsblattern.

\section{Inkubationszeit}

Schon Minuten nach Infektion tritt Juckreiz auf, die Entwicklung von Papeln erfolgt nach 6-8 Stunden.

\section{Leitsymptome}

Intensiv juckende Papeln.

\section{Symptome}

Die Symptomatik einer Zerkariendermatitis ist durch einen exzessiven Juckreiz geprägt, der schon wenige Minuten nach Eindringen der Zerkarien einsetzt, in den folgenden Stunden für 1-2 Tage seinen Höhepunkt erreicht und dann in den folgenden Tagen langsam wieder zurückgeht.

\section{Pathophysiologie}

Wenige Stunden nach Eindringen der Zerkarien entwickeln sich um die Parasitenlarven stark juckende ca. 0,5-1 cm große Papeln, die lokal eine zentrale Einschmelzung aufweisen können. Histologisch finden sich zunächst Blasenbildungen im Epithel und entzündliche Infiltrate um Gefäße im Corium; später kommt es dann zum Abheben der gesamten Epidermis von der Corium-Unterlage.

Häufig treten Komplikationen in Form von bakteriellen Sekundärinfektionen auf, die durch Kratzen hervorgerufen werden. Das durch die Zerkarien hervorgerufene Exanthem heilt innerhalb von 10-14 Tagen $\mathrm{ab}$.

\section{Immunantwort}

Eine durchgemachte Zerkariendermatitis hinterlässt keine Immunität, sondern führt zu einer Sensibilisierung, sodass bei folgenden Infektionen die Intensität der Hautreaktionen zunimmt.

\section{Differenzialdiagnose}

Stiche von blutsaugenden Arthropoden.

\section{Diagnostik}

\section{Untersuchungsmaterial}

Serum: Abnahme frühestens 8-10 Tage p. i.

\section{Diagnostische Verfahren}

Die Diagnose einer Zerkariendermatitis wird primär aufgrund des klinischen Bildes und der Anamnese (Baden in Naturgewässern) gestellt. Im Verlauf der Erkrankung kommt es zur Bildung spezifischer Antikörper, die sich bei stärker ausgeprägten Dermatitiden mithilfe von Immunfluoreszenz- und ELISA-Tests (Antigen: Zerkarien von Schistosoma mansoni) messen lassen. Da diese serologischen Tests jedoch erst bei
Abklingen des Krankheitsbildes positiv werden, kommt ihnen im Wesentlichen nur epidemiologische Bedeutung zu.

\section{Befund / Interpretation}

Ein falsch-negativer serologischer Befund kann durch eine $\mathrm{zu}$ frühe Serumabnahme oder beim Vorliegen nur einzelner Papeln zustande kommen.

Der Nachweis von Antikörpern ist nur in Zusammenhang mit dem kürzlich aufgetretenen klinischen Bild zu verwerten, da Antikörper gegen Zerkarien über Monate bis Jahre persistieren. Kreuzreaktionen gegen Schistosomen sind zu beachten.

\section{Therapie}

\section{Therapeutische Maßnahmen}

In Ermangelung einer ätiologischen Therapie können lediglich symptomatische Maßnahmen zur Linderung des Juckreizes getroffen werden. Diese bestehen in der Gabe oraler Antihistaminika, lokal eignen sich Juckreiz dämpfende Gele oder Lotionen. Bakterielle Sekundärinfektionen müssen $u$. $U$. antibiotisch behandelt werden.

\section{Epidemiologie \\ Verbreitung}

Zerkariendermatitiden kommen weltweit vor, in den letzten Jahren nehmen sie nach Mitteilung der WHO an Häufigkeit zu. In Deutschland sind sie in den Naturgewässern in Bayern seit Langem bekannt, in den letzten Jahren waren v. a. Baggerseen in der Oberrheinischen Tiefebene und der Bodensee von dieser Zoonose betroffen. Verursacher sind hier Zerkarien der Arten T. franki und T. ocellata. Soweit bisher bekannt sind Erstere nur in Südwestdeutschland verbreitet, T. ocellata kommt offenbar nur im südöstlichen Teil Deutschlands vor; Zwischenwirte für T. franki sind hier ausschließlich Schnecken der Gattung Radix, für T. ocellata Schnecken der Gattung Lymnaea.

\section{Wirtsbereich / Reservoir}

Der Mensch ist für Vogelzerkarien ein Fehlwirt, die eigentlichen Wirte sind verschiedene Wasservogelarten.

\section{Risikogruppen}

Das Auftreten von Vogelzerkarien hängt in erster Linie von der Ökologie der Zwischenwirt-Schnecken ab. Diese halten sich gewöhnlich im Uferbereich auf, so dass hier i. d. R. die meisten Zerkarien anzutreffen sind. Unter den Badegästen sind daher besonders Kinder von Zerkariendermatitiden betroffen, da sich diese lange im Flachwasserbereich aufhalten. Allerdings ist auch das tiefere Wasser nicht zerkarienfrei, Schnecken der Gattung Radix sind bis in $10 \mathrm{~m}$ Tiefe zu finden. Bei Teichwirten gilt die Zerkariendermatitis quasi als Berufserkrankung. 


\section{Transmission / Vektoren}

Die Infektion tritt beim Baden in Naturgewässern auf. Die Zerkarien werden durch optische, chemische und thermische Reize angelockt und dringen mithilfe ihres Penetrationsapparates aktiv in die Haut ein.

\section{Prävention / Impfstoffe}

Nach Untersuchungen von Haas und Mitarbeitern (2005) eignen sich folgende Lotionen und Salben als Repellents gegen Zerkarien:

- "Quallen+Sonnenschutz Canea“; kommerziell erhältliches Quallenschutzmittel, das auch gegen Zerkarien wirksam ist.

- Niclosamid in einer Konzentration von 0,05 \%, fein eingerührt in eine wasserfeste Sonnenschutzcreme. Herstellung durch den Apotheker.

\section{Ausbruchsmanagement}

Aufklärung über Biologie und medizinische Bedeutung der Badedermatitis; ggf. Empfehlung der o. a. Repellents. Bei massiv auftretenden Badedermatitiden muss ein Badeverbot in Betracht gezogen werden. Ökologische Maßnahmen gegen diese Parasitose sind nicht praktikabel.

\section{Meldepflicht}

Nach dem Infektionsschutzgesetz (IfSG) vom 1.1.2001 ist bei einer Badedermatitis weder die Erkrankung noch der Erregernachweis meldepflichtig. Eine Mitteilung an die zuständigen Behörden (Gesundheitsamt) ist jedoch von öffentlichem Interesse.

\section{Weiterführende Informationen}

\section{Referenzzentren / Expertenlaboratorien}

Offizielle Referenzzentren existieren nicht, spezielle Erfahrungen bestehen am Landesgesundheitsamt Baden-Württemberg in Stuttgart; als fachlich qualifiziert anzusehen sind darüber hinaus sämtliche parasitologischen und tropenmedizinischen Institutionen.

\section{Web-Adressen}

- CDC-Center for Disease Control and Prevention: http:// www.cdc.gov/ncidod/dpd/parasites/cercarialdermatitis/ default.htm

\section{Schlüsselliteratur}

1. Dönges J (1980) Parasitologie. Georg Thieme Verlag, Stuttgart

2. Haas W, van de Roemer A (1998) Invasion of the vertebrate skin by cercariae of Trichobilharzia ocellata penetration process and stimulating cues. Parasitology Research 84:787-795

3. Kimmig P, Meier M (1985) Parasitologische Untersuchungen, Diagnose und Klinik der Zerkariendermatitis, Hygienische Bedeutung für Badegewässer gemäßigter Zonen. Zbl Bakt Hyg I Abt Orig B 181:390-408

4. Müller V, Kimmig P (1994): Trichobilharzia franki n.sp. - die Ursache für Badedermatitiden in südwestdeutschen Baggerseen. Appl Parasitol 35:12-31

5. Neuhaus W (1952) Biologie und Entwicklung von Tri- chobilharzia szidati n.sp. (Trematoda, Schistosomatidae), einem Erreger von Dermatitis beim Menschen. Z Parasitenkd 15:203-266

\section{Zerkariendermatitis}

- Schistosomen

- Zerkarien

\section{Zervixkarzinom}

- Humane Papillomviren (HPV)

\section{Zervizitis}

- Chlamydia

\section{Ziegenpeter}

- Mumpsvirus

\section{Zika-Virus}

Flaviviren, seltene humanpathogene

\section{Zungenwürmer}

> Pentastomida

\section{Zwergbandwurm}

$\checkmark$ Hymenolepis

\section{Zwergdarmegel}

Darmegel

\section{Zwergfadenwurm}

- Strongyloides stercoralis

\section{Zwergfadenwurm-Infektion}

- Strongyloides stercoralis

\section{Zygomykose}

Mucorales 


\section{Zystitis}

Adenoviren

- Corynebacterium, sonstige Spezies

- Polyomaviren

- Staphylococcus (koagulasenegativ)

- Streptococcus agalactiae

\section{Zystitis, hämorrhagische}

Adenoviren

- Polyomaviren

\section{Zystizerkose}

- Taenien 